Review Article

\title{
Biotechnological Production of Polyhydroxyalkanoates: A Review on Trends and Latest Developments
}

\author{
Baljeet Singh Saharan, ${ }^{1,2}$ Anita Grewal, ${ }^{3}$ and Pardeep Kumar ${ }^{1}$ \\ ${ }^{1}$ Department of Microbiology, Kurukshetra University, Kurukshetra, Haryana 136 119, India \\ ${ }^{2}$ USDA-ARS Root Disease and Biocontrol Research Unit, Department of Plant Pathology, Lab No. 329 (A-D), \\ Washington State University, Pullman, WA 99164-6430, USA \\ ${ }^{3}$ Department of Biotechnology Engineering, UIET, Kurukshetra University, Kurukshetra, Haryana 136 119, India
}

Correspondence should be addressed to Baljeet Singh Saharan; baljeet.kuk@gmail.com

Received 20 November 2013; Accepted 2 January 2014; Published 24 February 2014

Academic Editors: A. Castañeyra-Perdomo and A. Clayton

Copyright (C) 2014 Baljeet Singh Saharan et al. This is an open access article distributed under the Creative Commons Attribution License, which permits unrestricted use, distribution, and reproduction in any medium, provided the original work is properly cited.

Polyhydroxyalkanoates (PHA) producers have been reported to reside at various ecological niches which are naturally or accidently exposed to high organic matter or growth limited conditions such as dairy wastes, hydrocarbon contaminated sites, pulp and paper mill wastes, agricultural wastes, activated sludges of treatment plants, rhizosphere, and industrial effluents. Few among them also produce extracellular by-products like rhamnolipids, extracellular polymeric substances, and biohydrogen gas. These sorts of microbes are industrially important candidates for the reason that they can use waste materials of different origin as substrate with simultaneous production of valuable bioproducts including PHA. Implementation of integrated system to separate their by-products (intracellular and extracellular) can be economical in regard to production. In this review, we have discussed various microorganisms dwelling at different environmental conditions which stimulate them to accumulate carbon as polyhydroxyalkanoates granules and factors influencing its production and composition. A brief aspect on metabolites which are produced concomitantly with PHA has also been discussed. In conclusion, exploring of capabilities like of dual production by microbes and use of wastes as renewable substrate under optimized cultural conditions either in batch or continuous process can cause deduction in present cost of bioplastic production from stored PHA granules.

\section{Introduction}

Ecological niches are positions designated to microbes where they perform individual role and interact all together to constitute ecosystem. Ecosystem is influenced by biotic and abiotic altercation as result of natural and anthropogenic activities. Microorganisms derive their food via diverse behavioural adaptation in environment to put together thriving existence. PHA accumulation is among such responses towards stress experienced by microorganisms residing at different ecological niches. Ecological niches like estuarine sediments, marine microbial mats, rhizosphere, groundwater sediments, and engineered ecosystems with fluctuating nutrient contents support the population actively involved in PHA accumulation to meet the metabolic energy requirements during starvation period and this concept can be implemented industrially to reduce the cost of biopolymers commercially with sustainable production processes [1].

We need to clearly understand ecological conditions prevailing and phenotypic characteristics of PHA producers. Waste disposal creates toxic, growth inhibiting, and unfamiliar environmental conditions [2]. Even though, at such state of physiological stress, PHA producers have been reported to be residing with properties like degrading dyes, aromatic compounds, and left over organic matter discharge from industries [3-7]. This implausible behavioural property can be considered towards industrial production aspects and issues related to removal of pollutants like PAHs, pesticides, dyestuffs, and so forth. In concern to increasing load of industrial waste on soil, researchers are trying all possible alternatives to use different wastes like textile effluent $[4,8]$, distillery effluent [9], dairy wastes [10-12], oil mill wastes [13], 
starchy waste $[14,15]$, paper mill wastes [16], animal residues [17], biodiesel waste by-product [18], and agricultural wastes [19], for PHA production. PHAs are produced under nutrient limiting conditions with excess of carbon [20] and get stored in polymerized form as inclusions bodies [21].

Last few years have contributed different aspects of bioplastic production where use of activated sludge as PHA producers [22] enriched via aerobic dynamic feeding (ADF) [23] and alternating anaerobic and aerobic system (AN/AE) [24] in sequencing batch reactor (SBR) and fermented effluents [25], exhibiting high BOD and COD value, as substrate have put on much importance. It is clearly understood that PHA production from mixed culture, enriched phosphate accumulating organisms (PAOs) [26, 27], enriched glycogen accumulating organisms (GAOs) [28], and Archaea [29] inhabiting low or high salt conditions rule out need of proper modelling of operational parameters to solve the issues associated with sterile conditions, synthetic medium preparation, maintenance of pure cultures, and high product cost. PHA as stored energy source increases survivability in Bacillus megaterium, a potential degrader and biocontrol agent, in water [30]. Stored copolyesters PHBHHx in Aeromonas hydrophila $4 \mathrm{AK} 4$ have been reported to survive off various environmental stresses like nutrient-limited conditions, cold treatment, UV-irradiation, ethanol, $\mathrm{H}_{2} \mathrm{O}_{2}$, and osmotic shocks [31]. PHA production enhances their feasibility to survive off the harsh conditions not being favourable for the normal growth of cells. Wastes like seafood cannery, rich in lipids, ammonia, and phosphates, are proved to be toxic to its inhabiting microorganisms. PHB accumulation had an advantage here not being only as stored material but also as alternate to metabolize excess fatty acids in order to cope with stress existed [32]. The property of storing carbon source intracellularly and utilizing the same to support activity of cells at later phase is possibly an advantage and it becomes of significant importance being commercially valuable byproduct.

On exhaustion of nutrients and with excess of carbon sources some microbes also produce extracellularly metabolites like rhamnolipids [33,34], alginate oligosaccharides [35], extracellular polymeric substances [36, 37], and biohydrogen $[38,39]$ along with intracellular PHA production stored as inclusion bodies. Studies have also reported how substrate composition, concentration, and its uptake modulate the production and composition of PHA polymer formed [4042]. $\mathrm{pH}$ [43] and temperature [44] have also been reported to affect PHA production and its composition. Thus, understanding of PHA production and its associated kinetics in respect to simultaneous production of other bioproducts may provide us with platform to design cost effective and efficient production unit.

\section{PHA Producers along with Their Ecological Niches}

2.1. Hydrocarbon Degraders as PHA Producers. Environmental stress, like presence of xenobiotic compounds, diverts physiological responses of residing organisms to produce more PHA [45]. Oil contaminated sites contain higher amount of carbon (84\%) and less in nitrogen contents $(>1 \%)$ creating a real prerequisite for cells to produce PHA [46]. Various bacterial strains capable of producing PHA while degrading oil have been isolated belonging to genera Pseudomonas, Acinetobacter, Sphingobacterium, Brochothrix, Caulobacter, Ralstonia, Burkholderia, and Yokenella from oil contaminated sites [3]. In an experiment, Ralstonia eutropha JMP 134 has been reported to produce PHB up to $50 \%$ of cell dry weight (CDW) when provided with growth inhibiting substances like phenol or sodium benzoate as carbon source under nutrient limiting state. Thus, it is of immense interest to prevent intoxication and explore microbial potential for production of valuable bioproducts [47]. Bacillus cereus FA11 isolated from trinitrotoluene contaminated soil (creating a necessary stress conditions) has been reported for the production of copolymer (3HB-co-3HV) up to $48.43 \%$ at $\mathrm{pH}$ 7 and temperature $30^{\circ} \mathrm{C}$ with glucose as carbon source [48].

In a case, extracellular deposition of PHB by mutant of marine bacterium Alcanivorax borkumensis SK2 has been reported grown on aliphatic hydrocarbon [49]. Construction of a bioprocess where waste comprising of toluene as sole carbon source enables the Rhodococcus aetherivorans IAR1 to produce copolymer $\mathrm{P}(3 \mathrm{HB}-\mathrm{co}-\mathrm{HV})$ and triacylglycerols (TAGs) resulting in cost reduction of production unit with effectual removal of waste material [50]. Similarly, in an another experiment of fed-batch fermentation with toluene as volatile aromatic hydrocarbon (carbon source) at flow rate of $0.42 \mathrm{~g} \mathrm{~L}^{-1} \mathrm{~h}^{-1}$ into a 7-L jar fermentor resulted in accumulation of $m c l$-PHA ( $58.9 \%$ by weight), a copolymer constituting $3 \mathrm{HD}$ (55.2\%), 3HO (26.8\%), 3HH (3.7\%), 3HDD (8.2\%), and 3HDD (6.1\%) by Pseudomonas fulva TY16 after $48 \mathrm{hr}$ of incubation, thus proving to be a potential candidate for bioconversion of petrochemical waste into valuable products like PHA [51].

2.2. Halophiles as PHA Producers. Archaea are considered as extremophiles since reported to reside at hot springs, marshlands, oceans, salt lake, and so forth and have been reported to produce PHA. These organisms require salts to sustain their growth. They grow optimally at $5 \%$ and at least tolerate $10 \%$ of salt $\mathrm{NaCl}(\mathrm{w} / \mathrm{v})$ [69]. The first case of PHB accumulation by archaea had been reported in 1970 from Dead Sea named as Halobacterium marismortui analysed by freezefracture technique [70]. Extremely halophilic archaebacteria (Halobacteriaceae) produce $\mathrm{PHB}$ under nutrient-limited conditions and abundant carbon sources [71]. Haloferax mediterranei, which grows at $25 \%(\mathrm{w} / \mathrm{v})$ of salt concentration, produces 60 to $65 \%$ PHA of its cell dry weight (CDW) when grown in phosphate limiting conditions and glucose or sucrose as best carbon source [72]. Halomonas boliviensis LC1, a moderate Halophile growing at $3-15 \%(\mathrm{w} / \mathrm{v})$ of salt concentration, produces higher amount of $\mathrm{PHB}$ up to $56 \%$ of CDW, when grown on starch hydrolysate as substrate. Pretreatment results in conversion of higher complex form of organic substances into easily consumable form (simpler form). $H$. boliviensis LC1 preferably utilizes maltose from starch hydrolysates. It has been found that oxygen limitation 
enhances the PHA production [73]. H. boliviensis LC1 could produce high amounts of $\mathrm{PHB}$ up to $88 \%$ of $\mathrm{CDW}$ in the presence of excess of butyric acid and sodium acetate as carbon sources under nutrient-limited conditions (yeast extract at $0.1 \%, \mathrm{w} / \mathrm{v}$ ) during stationary phase [74]. Similarly, when Halopiger aswanensis (strain $56^{\mathrm{T}}$ ) was grown under nutrient-limited conditions (and excess carbon), the cells accumulated large amounts of polyhydroxybutyrate [75].

Study on enzyme, PHA synthase, activity of extremely halophilic archaeon, Haloarcula marismortui, has suggested that PHA is constitutively expressed independent of nutrient rich or nutrient-limited conditions [76]. Similarly, another report shows that $\mathrm{PHB}$ and $\mathrm{P}(\mathrm{HB}-\mathrm{Co}-\mathrm{HV})$ producers like Halococcus sp., Halorubrum sp., Halobacterium noricense DSM 9758, and haloakaliphiles (Natronobacterium gregoryi NCMB $2189^{\mathrm{T}}$, Natronococcus occultus DSM $3396^{\mathrm{T}}$ ) require alkaline and salt conditions irrespective of complex medium and nutrient-rich or nutrient-limited conditions [77]. Most importantly, extremely halophilic archaeon, Haloarcula marismortui, has been reported to produce PHA under shake flask conditions using vinasses (by-product of ethanol industries) as substrate. Utilization of $10 \%$ raw vinasses and $100 \%$ pretreated vinasses resulted in $\mathrm{PHB}$ production up to $24 \%$ and $30 \%$ of CDW, respectively [29]. In a review [78] described PHA producing halophiles and concluded that there is need of understanding synthetic and regulatory mechanisms controlling polymer synthesis to overcome the economical competition at industrial scale.

2.3. Photosynthetic Bacteria as PHA Producers. Cyanobacteria are photosynthetic prokaryotes with short generation time, reported to produce PHA by oxygenic photosynthesis. Studies have led to conclude that some cyanobacteria have natural capabilities to store PHAs. Some Cyanobacteria were screened for the presence of PHA which was reported to be species specific, mostly producing $\mathrm{PHB}$, stimulated by phosphorus deficient conditions and presence of excess amount of reducing equivalents [79]. Synechococcus sp. MA19 (accumulated up to 55\% of CDW), Nostoc muscorum, and Spirulina platensis produced $\mathrm{PHB}$ under phosphate limited conditions [80, 81]. Phosphorus deficient conditions and supplementation of $0.4 \%$ of acetate resulted in accumulation of PHA up to $29 \%$ of CDW by pregrown cells of Synechocystis sp. PCC 6803 in glucose [82].

Synechocystis sp. UNIWG, and Synechocystis sp. PCC 6803 accumulated PHB up to $14 \%$ and $15 \%$ of CDW under nitrogen limiting conditions, respectively [83, 84]. Synechocystis sp. PCC 6803 when subjected to nitrogen, phosphorus, and gas-exchange limiting conditions $\mathrm{PHB}$ production was enhanced [85]. Sulfur deprived conditions enhanced PHB content by 3.5-fold [86]. A study showed that Nostoc muscorum could produce $\mathrm{PHB}$ five times higher under mixotrophy, chemoheterotrophy with nitrogen-limiting state than what was produced under photoautotrophic conditions [87]. Addition of exogenous carbon sources, $\mathrm{pH}$, light-dark cycles, and phosphorus and nitrogen status were found to regulate accumulation of $\mathrm{PHB}$ in Nostoc muscorum [87]. Use of Cyanobacteria ability to produce $\mathrm{PHB}$ with energy obtained from sunlight can result in reduction of cost and $\mathrm{CO}_{2}$ a "greenhouse gas" as well [83].

2.4. Plant Growth Promoting Rhizobia (PGPR) as PHA Producers. Soil adjacent to roots of plants is termed rhizosphere which may harbour microbes enhancing the growth of roots and plants by secreting extracellularly metabolites [88]. Root exudates release nutrients to its surrounding rhizosphere which in turn serve as hot-spot for microbial interaction and thus, recycling of nutrients takes place [89]. It has been clearly elucidated that rhizosphere has hidden or untapped reservoirs for PHA accumulators in addition to PGPR and antagonistic effect. Some microorganisms, Burkholderia terricola, Lysobacter gummosus, Pseudomonas extremaustralis, Pseudomonas brassicacearum, and Pseudomonas orientalis have been reported as PHA producers based on PCR technique having phaC as targeted gene [90].

Azospirillum brasilense is a plant growth promoting rhizobacterium (PGPR) that is being increasingly used in agriculture in a commercial scale. Recent research has elucidated key properties of $A$. brasilense that contribute to its ability to adapt to the rhizosphere habitat and to promote plant growth. They include synthesis of the auxin indole-3-acetic acid, nitric oxide, carotenoids, and a range of cell surface components as well as the ability to undergo phenotypic variation. Storage and utilization of poly- $\beta$-hydroxyalkanoate polymers are important for the shelf life of the bacteria in production of bioinoculants, products containing bacterial cells in a suitable carrier for agricultural use. It was reported that mutants of phaC and phaZ genes in Azospirillum brasilense were somehow less tolerant to stress conditions such as UV-radiations, heat, osmotic pressure, osmotic shock, $\mathrm{H}_{2} \mathrm{O}_{2}$ presence, and desiccation, in comparison to wild type [91, 92]. Production of PHA holds advantageous characteristics towards enhanced root colonization, plant growth promotion, survivability, chemotaxis, motility, and cell multiplication. PHA production is also very effectual in improving reliability, efficiency, and shelf life of inoculants of A. brasilense [91]. Based on cultivation-dependent methods, earlier it was reported that rhizosphere has low PHA production in comparison to nonrhizosphere soil [93, 94]. Cultivation-independent and molecular techniques allowed us to conclude that wheat, oilseed rape, and sugar beet rhizosphere have more PHA production [95-97]. Root of oily and carbohydrate producing plants harbours more PHA producers as supported by the fact the root exudates contain abundant source of carbon and inorganic nutrients being in limited state [90].

A relationship between $\mathrm{PHB}$ production and survivability during starvation in Sinorhizobium meliloti within alfalfa was established, where they produced PHB up to $0.25 \mathrm{pg}^{\text {cell }}{ }^{-1}$ to support multiplication and survival during starvation period. Later, $\mathrm{PHB}$ accumulation is found to be quantitative trait as being differentially regulated by different genes among rhizobia [98]. PHA accumulation in nodule gets induced under low oxygen state or decreased redox potential as studied in Azotobacter beijerinckii, Azotobacter insignia, and Rhizobium ORS571 [99-102]. The rhizobia include the genera Sinorhizobium, Rhizobium, Bradyrhizobium, Mesorhizobium, 


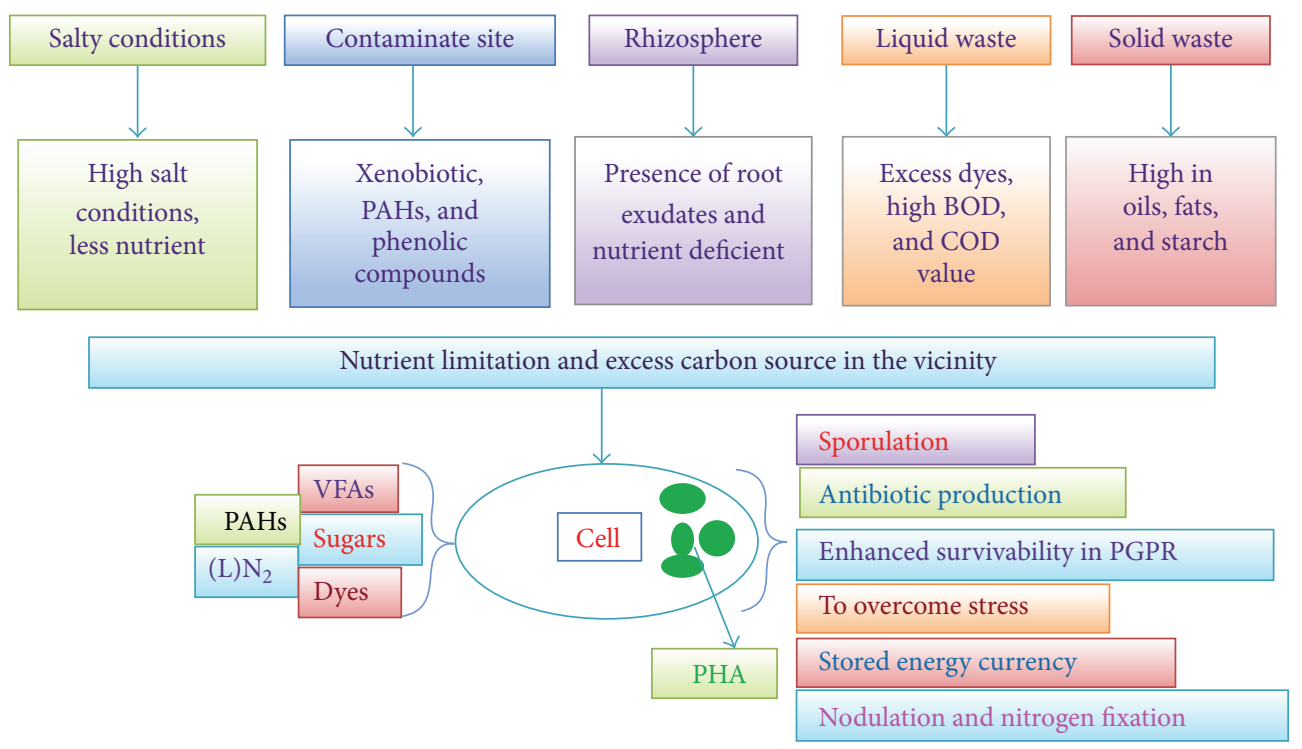

FIGURE 1: A diagram representing different ecological stress conditions which favour PHA accumulation to sustain the metabolic activities at optimal conditions.

and Azorhizobium which form nitrogen fixing nodule in legumes. Stored PHA fuels rapid colonization, efficient nodulation, and nitrogen fixation. The accumulation of PHB has been reported in both rhizobia associated with roots actively involved in nodulation (rhizobia-legume symbiosis) or free living nitrogen fixing organisms. Ability to accumulate PHB is directly correlated to type of nodule being formed, that is, determinate or indeterminate differing in possession of persistent meristem [103]. Proteobacteria and Firmicutes were isolated from root nodules of eight leguminous plants reported to be accumulating $\mathrm{PHB}$ [104].

2.5. Antibiotic Producers as PHA Producers. Streptomyces are aerobic, gram positive filamentous bacteria known for their valuable metabolites production. Streptomyces are reported for PHA production intracellularly in granular form working as supplier of carbon units for antibiotic synthesis and sporulation [105]. Nitrogen supplementation and increased carbon source showed positive effect on $\mathrm{PHB}$ production in Streptomyces griseorubiginosus and produced up to $9.5 \%$ of mycelial dry mass at the early stationary phase [106]. PHB production in different strains of Streptomyces has been studied and investigated for its role in antibiotic production.

Later, reports showed that production of PHB occurred in Streptomyces coelicolor A3 (2) M145 during exponential phase and supplied acetyl-CoA being precursors for the production of three different antibiotics namely actinorhodin, $\gamma$-actinorhodin, and undecylprodigiosin at stationary phase [107]. During synthesis of actinomycin A, stored PHB was utilized in Streptomyces antibioticus [108]. Similarly, it was reported that PHB served as supplier of acetoacetyl-Co-A and butyryl-Co-A for the production of chloramphenicol in Streptomyces venezuelae and macrolide ascomycin FK520 in Streptomyces hygroscopicus, respectively $[109,110]$. PHB being a primary metabolite serves as building blocks for the synthesis of metabolites [111]. Streptomyces aureofaciens 84/25, S. griseus, S. olivaceous, S. fradiae, S. parvus, S. albus, and so forth are reported to produce $\mathrm{PHB}$ with glucose as carbon source $[105,107]$. A diagram representing different ecological stress (suboptimal) conditions which favour PHA accumulation to sustain the metabolic activities at optimal conditions is being depicted as in Figure 1.

2.6. Activated Sludge as PHA Producers. Continuous inflow of industrial wastes from industry is of environmental concern in reference to its toxic pollutant constituents. Wastes are often rich in organic contents and less rich in nutrient contents. This state of unbalanced nutrients supports growth of PHA producers but has minimal consumption rate of organic matter (substrate) and storage rate $[112,113]$. These issues were resolved using pretreated waste of several kinds when subjected to different treatments like thermal treatment, anaerobic treatment, enzymatic treatment, mechanical treatment, and so forth. Treated waste results in having simpler forms like volatile fatty acids (VFAs) and sugar moieties which are easy to uptake and store by cells. Threestage processes have been followed by some researchers $[15,114,115]$ where treatment of wastes constitutes first step followed by enrichment of activated sludges and final batch production of PHA using treated waste as substrate and enriched activated sludge as inocula. Activated sludge can be enriched by AN/AE and ADF in SBR [24]. The composition of VFAs influences composition and microstructure of polymer. So, it is of prior importance to consider. PHA production under aerobic microenvironment showed that consortium accumulated more PHA (39.6\%) with fermented food waste than with unfermented food waste $(35.6 \%)$ as substrate. Because the fermented food waste contained ready to take up VFA in comparison to unfermented food waste with complex organic substrates to be degraded before being 
used up [116]. Waste of various origins as substrate with the treatment applied and resulting possible constituents of treated waste and percentage of PHA obtained are given in Table 1.

2.6.1. Anaerobic and Aerobic System. Waste treatment by alternating aerobic and anaerobic conditions like enhanced biological phosphate removal (EBPR) can be an effective process in respect to concurrent implementation of PHA production using the enriched activated sludge. Synthesis of PHA by PAOs was first reported by Wallen and Rohwedder [117]. Phosphorus accumulating organisms (PAOs) accumulate PHA with energy derived from polyphosphate breakdown (release of phosphorus) under anaerobic phase and later utilize the stored form (PHA) to restore polyphosphate and sustain normal metabolic activities [118, 119]. Also, having phosphate released into stream could be useful to field cultivating crops as fertilizers [120]. Microlunatus phosphovorus from activated sludge was studied for its capabilities to store PHB under AN/AE conditions subjected to different growth conditions and carbon sources. PAOs usually take up short fatty acids which are converted to polymeric form of energy and further they were concluded as potential candidate for PHA production [27].

Different glycogen accumulating organisms (GAOs) like Candidatus competibacter phosphatis and Defluviicoccus vanus $[28,121-124]$ within SBR under AN/AE conditions have been reported in literature. GAOs utilize glycogen to derive energy for uptake of volatile fatty acids and subsequently convert them into PHA via acetyl-CoA and propionylCoA. Glycogen is also converted to PHA. Under aerobic conditions, stored PHA is utilized to sustain the normal functions of cell and restore glycogen. Stored glycogen is utilized under both anaerobic and aerobic conditions with different stoichiometry. $3 \mathrm{HB}$ and $3 \mathrm{HV}$ up to $49 \%$ of CDW were produced in anaerobic conditions, whereas only $3 \mathrm{HB}$ up to $60 \%$ of $\mathrm{CDW}$ was produced in aerobic conditions suggesting that different metabolic routes were followed by GAOs under alternating anaerobic and aerobic conditions [121]. GAOs have been reported to accumulate PHA using fermented cane molasses $[28,125]$ and synthetic carbon sources like acetate and propionate as well [126-128].

Bacterial richness and dynamics of PHAs producers from activated sludge enriched in sequencing batch reactor fed with mixture of molasses and acetic acids were explored under AN/AE conditions based on PCR-DGGE technique [129]. It was investigated that excess activated sludge consisting mainly of PAOs and GAOs could be an innovative alternative to typical axenic PHA production in reference to cost and flexibility in operating conditions. PHA productivity of $0.5-2.19 \mathrm{~g} \mathrm{PHA} \mathrm{L}^{-1} \mathrm{~h}^{-1}$ and intracellular content of 21$51 \%$ under defined conditions of $\mathrm{pH}$ and anaerobic contact time by PAOs and GAOs, respectively, were reported [130]. Unlike ADF suitability to treat effluents having high organic content and deficient in nutrients, AN/AE system could be of choice with industrial effluent constituting high carbon and high phosphorus contents. Thus, implementing anaerobic conditions followed by aerobic conditions could result in to higher productivity when compared to under separate anaerobic and aerobic conditions [131].

2.6.2. Aerobic Dynamic Feeding System (ADF). Alternate "feast" and "famine" conditions in SBR are another concept to enrich the mixed culture [132]. Feast condition is period of excess carbon and storage of carbon in the form of polymers and famine condition is period of carbon deficient and consumption of stored polymer to sustain growth. Famine conditions result in less metabolic RNA and enzymatic activity of cells. This retarded metabolic status of cells when subjected to feast conditions results in storage of carbon [133]. With use of diazotrophic mixed cultures using acetic and propionic acids as carbon sources under ADF strategy in SBR resulted in production of $\mathrm{PHB}$ and $\mathrm{P}(3 \mathrm{HB}-\mathrm{co}-\mathrm{HV})$ [134]. Similarly when activated sludge was enriched by ADF under different nitrogen regimes, it had been notified that PHA accumulated was always higher in activated sludge enriched under nitrogen deficient conditions [135]. These reports were significant in relation to use of nitrogen deficient wastewater but abundant in carbon contents for production of valuable bioproduct like PHA.

Production of PHA up to $89 \%$ of CDW was reported within $7.6 \mathrm{hr}$ by open mixed cultures, dominated by $\gamma$ proteobacterium, in acetate-fed sequencing batch reactor enriched under feast and famine conditions [136]. They also suggested that engineering of ecological niche rather than the organisms could be an alternative promising approach to explore capabilities like PHA accumulation. Successful production of copolymer by dominating group of $\beta$ Proteobacteria constituting $70 \%$ of $\mathrm{HB}$ monomers and $30 \%$ of HV monomers from bio-oil obtained after pyrolysis of chicken-beds by mixed microbial culture had been elucidated under feast-famine conditions [137].

Recently, an efficient method of PHA production was notified where acetate as carbon source and photosynthetic consortium of algae as source of oxygen along with bacteria were cultured under feast and famine conditions [138]. This opens up a new possibility of using sunlight driven PHA accumulation without any external oxygen supply to reduce the cost of production. In a review, the authors clearly detailed about techniques and trends towards PHA accumulation with use of mixed culture from waste material as low cost substrate under transient feast and famine conditions and aerobic-anaerobic conditions in SBR. Further, it has been reported that nonsterile reactors and little process control eliminate traditional bottlenecks of continuous monoseptic fermentations [23].

\section{Factors Influencing PHA Production and Composition}

3.1. Nutrients Availability and Optimization. Nutrient limitation leads to increase in PHB production whereas high nitrogen state directed increase in biomass growth with no PHB production [139]. Low concentration of phosphorus and nitrogen is favourable to PHB accumulation rather than complete underprovided conditions. PHA production 
TABLE 1: Waste of various origins as substrate with the treatment applied and resulting in possible constituents of treated waste and percentage of maximum PHA obtained.

\begin{tabular}{|c|c|c|c|c|c|}
\hline Substrate & Treatment applied & Possible constituents & Microorganisms & $\begin{array}{l}\text { Maximum PHA } \\
\text { produced }\end{array}$ & References \\
\hline Sugarcane molasses & Acidogenic fermentation & VFAs & $\begin{array}{l}\text { Glycogen } \\
\text { accumulating } \\
\text { organisms }\end{array}$ & $\begin{array}{l}0.47-0.66 \mathrm{C}- \\
\text { mol PHA/C-mol of } \\
\text { total carbon } \\
56-70 \text { mol- } \% 3 \mathrm{HB} \text {, } \\
13-43 \mathrm{~mol}-\% 3 \mathrm{HV} \text {, } \\
1-23 \mathrm{~mol}-\% 3 \mathrm{HHx} \text {, } \\
0-2 \mathrm{~mol}-\% \\
3 \mathrm{H} 2 \mathrm{MB} \text {, and } \\
3 \mathrm{H} 2 \mathrm{MV}\end{array}$ & {$[28]$} \\
\hline $\begin{array}{l}\text { Cassava starch } \\
\text { wastewater }\end{array}$ & Acidogenic fermentation & $\begin{array}{l}\text { Acetate, butyrate acids, } \\
\text { propionate, } \mathrm{pH}-5.3 \text {, and } \\
\text { high COD value. }\end{array}$ & $\begin{array}{l}\text { Cupriavidus sp. } \\
\text { KKU38 }\end{array}$ & PHB; $85.53 \%$ of CDW & {$[52]$} \\
\hline $\begin{array}{l}\text { Sugar refinery waste } \\
\text { (cane molasses) }\end{array}$ & $\begin{array}{l}\text { Acid treatment and activated } \\
\text { charcoal }\end{array}$ & Carbohydrate (4\%) & $\begin{array}{l}\text { Pseudomonas } \\
\text { aeruginosa }\end{array}$ & PHB; $62.44 \%$ of CDW & {$[53]$} \\
\hline $\begin{array}{l}\text { Cynodon dactylon } \\
\text { grass and syzygium } \\
\text { cumini seed; }\end{array}$ & $\begin{array}{l}\text { Pulverization followed by } \\
\text { hydrolysis }\end{array}$ & Glucose & $\begin{array}{l}\text { SP-Y1 and Ralstonia } \\
\text { eutropha }\end{array}$ & $\begin{array}{l}\text { SP-Y1 (PHB) } \\
\text { H.S } \\
26.76 \% \text { of CDW } \\
\text { H.G } \\
\quad 41.7 \% \text { of CDW } \\
\text { R. eutropha (PHB) } \\
\text { H.S } \\
\quad 42.2 \% \text { of CDW } \\
\text { H.G } \\
\quad 28.97 \% \text { of CDW }\end{array}$ & {$[54]$} \\
\hline $\begin{array}{l}\text { Milk and icecream } \\
\text { wastewater }\end{array}$ & Acidogenic fermentation & VFAs & Activated sludge & $\begin{array}{l}0.25 \mathrm{~kg} \text { PHA } / \mathrm{kg} \text { of } \\
\text { COD }\end{array}$ & {$[11]$} \\
\hline Palm oil mill effluents & Acidogenic fermentations & $\begin{array}{l}\text { Acetate, propionate, and } \\
\text { butyrate }\end{array}$ & $\begin{array}{l}\text { Ralstonia eutropha } \\
\text { JMP } 134\end{array}$ & $\begin{array}{l}\text { At } 20 \text { th and } 40 \text { th hr } \\
0.75 \mathrm{~g} \text { PHA/g CDW } \\
\text { At } 40 \text { th and 60th hr } \\
0.41 \mathrm{~g} \text { PHA/g CDW }\end{array}$ & {$[55]$} \\
\hline Rice straw & Acidic treatment & $\begin{array}{l}\text { Pentose sugars and } \\
\text { hemicelluloses }\end{array}$ & $\begin{array}{l}\text { Bacillus firmus NII } \\
0830\end{array}$ & PHB; $89 \%$ of CDW & {$[56]$} \\
\hline $\begin{array}{l}\text { Seed oil of Jatropha } \\
\text { curcas }\end{array}$ & Saponification & $\begin{array}{l}\text { Oleic acid, linoleic acid, } \\
\text { and palmitic acid }\end{array}$ & $\begin{array}{l}\text { Pseudomonas } \\
\text { oleovorans ATCC } \\
29347\end{array}$ & $\begin{array}{l}\mathrm{P}(3 \mathrm{HB}-c o-3 \mathrm{HV}) \\
26.06 \% \mathrm{CDW}\end{array}$ & {$[57]$} \\
\hline $\begin{array}{l}\text { Hemicellulosic } \\
\text { feedstock (sugarcane } \\
\text { bagasse) }\end{array}$ & $\begin{array}{l}\text { Acid hydrolysis, boiling, } \\
\text { precipitation, and activated } \\
\text { charcoal }\end{array}$ & $\begin{array}{l}\text { Xylose, arabinose, } \\
\text { glucose, and acetic acids }\end{array}$ & $\begin{array}{l}\text { Burkholderia cepacia } \\
\text { IPT } 048 \text { and Bacillus } \\
\text { sacchari IPT } 101\end{array}$ & $\begin{array}{l}\text { IPT } 048 \\
\text { PHB; } 62 \% \text { of CDW } \\
\text { IPT } 101 \\
\text { PHB; } 53 \% \text { of CDW }\end{array}$ & {$[58]$} \\
\hline $\begin{array}{l}25 \% \text { and } 50 \% \text { of vinasse } \\
\text { (ethanol industry } \\
\text { waste) }\end{array}$ & Activated charcoal & $\begin{array}{l}\text { Sucrose, oxalate, lactate, } \\
\text { malate, and pyruvate }\end{array}$ & $\begin{array}{l}\text { Haloferax } \\
\text { mediterranei }\end{array}$ & PHB; $70 \%$ of CDW & {$[59]$} \\
\hline Paper mill wastewater & Acidogenic fermentation & VFAs & Activated sludge & $\begin{array}{l}\text { PHB and PHV; } 48 \% \\
\text { of SDW }\end{array}$ & {$[16]$} \\
\hline
\end{tabular}

HB: hydroxybutyrate, HV: hydroxyvalerate, HHx: hydroxyhexanoate, 3H2MB: 3-hydroxy-2-methylbutyrate, 3H2MV: 3-hydroxy-2-methylvalerate, PHB: poly3-hydroxybutyrate. 
under low nitrogen and phosphorus concentration was reported to be $45.1 \%$ and $54.2 \%$ of CDW, respectively. Optimizing the same cultural conditions enhanced copolymer $\mathrm{P} 3(\mathrm{HB}-\mathrm{co}-\mathrm{HV}$ ) content by $14 \%$, constituting $88 \%$ of $\mathrm{HB}$ and $8 \%$ of $\mathrm{HV}$ [116]. A study demonstrated that external metabolic limitation in addition to internal limitation could decrease the storage rate [41]. Brachymonas sp. P12, denitrifying phosphorus-removing bacteria, obtained from winery waste capable of producing $\mathrm{PHB}$ was studied to optimize the conditions for PHA production considering factors like oxygen or nitrate as electron acceptor, nitrogen concentration $\left(\mathrm{NH}_{4} \mathrm{Cl}\right)$, phosphorus $\left(\mathrm{KH}_{2} \mathrm{PO}_{4}\right)$, and carbon concentration (acetate). C-excess conditions had negative effect on PHB accumulation when compared to C-limited conditions in reference to its specific production rate. Thus, aerobic, C-limited, $\mathrm{N}$-excess or $\mathrm{N}$-limited, and P-limited or $\mathrm{P}$-excess affected the growth-associated production of PHA [140].

Carbon/nitrogen $(\mathrm{C} / \mathrm{N})$ ratio is a very important variable to consider during PHA production supported by the fact that optimum $\mathrm{C} / \mathrm{N}$ ratio of 25 showed maximum PHA productions [141]. PHB production increased by 1.8 -folds with $\mathrm{C} / \mathrm{N}$ ratio of 28.3 , where sucrose as carbon source, ammonium sulfate as suitable nitrogen source, optimum $\mathrm{pH}$ of 6.5 , and temperature of $33^{\circ} \mathrm{C}$ were provided in batch culture of Alcaligenes latus ATCC 29713 [142]. Oleic acid as carbon source (with $\mathrm{C} / \mathrm{N}$ ratio of 20) enhanced PHA production in Cupriavidus sp. USMAA2-4 [143]. High C/N ratio of 144 for PHA production by activated sludge was found to be effective [144].

Designing of cultural conditions allows us to use suitable nutrients in order to enhance the PHA production. BoxBehnken design was undertaken to optimize the cultural conditions in respect to maximum PHB production. The authors considered cultivation parameters like ammonium sulfate as nitrogen source, glucose as carbon source, $\mathrm{KH}_{2} \mathrm{PO}_{4}$, and $\mathrm{Na}_{2} \mathrm{HPO}_{4}$ as phosphorus source to successfully implement the idea which leads to maximum production of $1.45 \mathrm{~g} \mathrm{~L}^{-1}$ in Bacillus megaterium SW1-2 with $75 \%$ validity confirmed using verification experiment [145]. Similarly, PHB production by Haloarcula sp. IRU1 in batch culture with various constituents of production medium using Taguchi experimental design was done. Reports inferred that glucose at $2 \mathrm{~g} \mathrm{~L}^{-1}$, nitrogen at $0.2 \mathrm{~g} \mathrm{~L}^{-1}$, phosphorus as $\mathrm{KH}_{2} \mathrm{PO}_{4}$, and temperature at $42^{\circ} \mathrm{C}$ resulted in the highest PHB accumulation up to $63.0 \%$ of CDW based on ANOVA. Glucose was actively utilized for PHB production; that is, carbon source plays a significant role in PHB production [146]. A five-levelthree-factor central composite rotary design was employed to optimize magnetic field, $\mathrm{NH}_{3}-\mathrm{N}$, and initial $\mathrm{pH}$ on the PHA production by activated sludge under ADF strategy which led to accumulation up to $49.5 \%$ of CDW [147]. Central composite rotary design was also employed to optimize the production of PHB from dairy waste, rice bran, and sea water as nutrients source by Bacillus megaterium SRKP-3 [12]. Factorial design was adopted to study effect of ammonium, phosphate, and yeast extract on PHB production by Halomonas boliviensis [148]. The authors also reported high productivity of PHB by Halomonas boliviensis in fed-batch culture [149]. Recently, to evaluate the influence and specific function of eight important factors (iron, glucose concentration, VFA concentration, VFA composition, nitrogen concentration, phosphorous concentration, $\mathrm{pH}$, and microenvironment) on the PHA production, design of experimental methodology using Taguchi orthogonal array was implemented [150].

Different acids as possible carbon source showed very prominent result on PHA production. The supplementation by citrate $(0.5 \%)$ and acetate $(0.5 \%)$ individually under phosphate deficient conditions, followed by 5 days of dark incubation, results in $51 \%$ and $77 \%$ of PHB production, respectively, in case of Aulosira fertilissima [151]. PHB produced in acetate medium was 7 times higher than what was reported in succinate media by Rhodobacter sphaeroides KD131 [152]. Butyric acid showed the highest PHB productivity of 33\% followed by acetic acid (32\%), mixture of acids (butyric acid and acetic acid), and then propionic acid (11\%). Mixture of butyric and acetic acids showed higher productivity than propionic acid since latter involved complex metabolism for its conversion to PHB [153]. VFA at concentration of $9 \mathrm{~g} \mathrm{~L}^{-1}$ and acetate : propionate : butyrate at ratio of $20: 10: 70$ showed maximum PHB accumulation [150]. Different types of wastes used as substrate and microorganisms as PHA producers with their respective maximum PHA produced has been depicted in Table 2 .

The composition of polymers was found to be varying with type of substrate used [136]. If acetate is used as carbon source, it results in production of copolymer $\mathrm{P}(3 \mathrm{HB}-\mathrm{co}-3 \mathrm{HV})$ with higher $\mathrm{HB}$ contents, whereas propionate (as carbon source) results in higher HV content. On the other hand, the butyrate results in the formation of $\mathrm{HB}$ units only. Mixture of all acids resulted in copolymer production with higher HV contents [26]. Butyrate and acetate were much effective towards polymer composition in comparison to propionate [150].

PHA polymer composition also varied with use of acidogenic effluents (AE). Contents of $\mathrm{HB}$ derived from synthetic acids (SA) and AE were found to be $91 \%$ and $84 \%$, respectively, whereas HV derived from SA and AE was found to be $5 \%$ and $12 \%$, respectively [25]. The authors also concluded that acidogenic effluents could be alternative and low cost substrate for $\mathrm{P}(3 \mathrm{HB}-\mathrm{co}-3 \mathrm{HV})$ production with higher concentration of $\mathrm{HB}$ and almost similar properties as obtained with synthetic acids. When PHA producers were subjected to SBR (with propionate) and SBR (with acetate), it resulted in production of copolymer $\mathrm{P}(3 \mathrm{HB}-\mathrm{co}-3 \mathrm{HV})$ and polymer (3HB), respectively [154]. 1-Pentanol as $3 \mathrm{HV}$ precursors together with $\gamma$-butyrolactone or 1,4-butanediol as $3 \mathrm{HB}$ precursors significantly produced terpolyester of different composition (monomers). Polymer obtained had five different monomers $(3 \mathrm{HB}, 3 \mathrm{HV}, 3 \mathrm{H} 2 \mathrm{MV}, 3 \mathrm{H} 2 \mathrm{MB}$, and $3 \mathrm{HHx}$ ) with different proportions using fermented and synthetic VFAs as substrate and using GAOs as cultural organism and decomposition temperature of polymers obtained was independent of monomer compositions [28]. PHA yield and composition produced by Pseudomonas aeruginosa $47 \mathrm{~T} 2$ Depends on carbon, nitrogen, phosphorus sources, and incubation temperature [155]. 
TABLE 2: Different types of wastes used as substrate and microorganisms as PHA producers with their respective maximum PHA produced.

\begin{tabular}{|c|c|c|c|}
\hline Substrate type & Microorganisms & Type and maximum PHA produced & Reference(s) \\
\hline \multirow[t]{2}{*}{$\begin{array}{l}\text { Food processing wastewater and } \\
\text { distillery spentwash }\end{array}$} & \multirow[t]{2}{*}{ Activated sludge } & $\begin{array}{l}\text { D.J.G.B.D.S; PHB; } 42.3 \% \text { of CDW } \\
\text { R.R.G.B.D.S + DAHP; PHB; } 67 \% \text { of } \\
\text { CDW }\end{array}$ & \multirow[t]{2}{*}[19]{} \\
\hline & & F.F.P.I.W; PHB; 39.1\% of CDW & \\
\hline Cassava wastewater & Pseudomonas aeruginosa & PHA; $39 \%$ of CDW & {$[60]$} \\
\hline Maple sap & Alcaligenes latus & PHB; $77.6 \% \pm 1.5$ of $\mathrm{CDW}$ & {$[61]$} \\
\hline Domestic wastewater & Enterobacter aerogenes $12 \mathrm{Bi}$ strain & PHB; Up to $90 \%$ of CDW & {$[62]$} \\
\hline Molasses and dye textile dye & Sphingobacterium sp. ATM & PHD; $64 \%$ of CDW & {$[2]$} \\
\hline Fatty wastes & $\begin{array}{l}\text { Lipolytic bacterial strains } \\
\text { (Acinetobacter sp., Pseudomonas sp., } \\
\text { Bacillus sp.) }\end{array}$ & $\begin{array}{l}3 \mathrm{HB}, 3 \mathrm{HV}, 3 \mathrm{Hx}, 3 \mathrm{HD}, 3 \mathrm{HDD} \text {, and } \\
3 \mathrm{HO} ; 0.1 \% \text { to } 32.2 \% \text { of } \mathrm{CDW}\end{array}$ & {$[63]$} \\
\hline $\begin{array}{l}\text { Glycerine pitch + 1,4-butanediol } \\
\left(5 \mathrm{~g} \mathrm{~L}^{-1}\right)\end{array}$ & Cupriavidus sp. USMAHM13 & $\mathrm{P}(3 \mathrm{HB}-c o-4 \mathrm{HB}) ; 49 \%$ of CDW & {$[64]$} \\
\hline Starchy wastewater & Alcaligenes eutrophus ATCC17699 & $\begin{array}{l}\mathrm{PHB} \text { and } \mathrm{P}(3 \mathrm{HB}-c o-3 \mathrm{HV}) \\
50 \mathrm{~g} \text { PHA } 100 \mathrm{~g} \text { TOC }\end{array}$ & {$[14]$} \\
\hline Vinasse & Haloarcula marismortui & PHB; $23 \%$ of CDW & {$[29]$} \\
\hline Waste potato starch & Ralstonia eutropha NCIMB 11599 & PHB; $94 \mathrm{~g} \mathrm{~L}^{-1}$ & {$[65]$} \\
\hline Textile effluent and mixture of dyes & Sphingobacterium sp. ATM & PHD; $66 \%$ of CDW & {$[4]$} \\
\hline Maple hemicellulosic hydrolysate & Burkholderia cepacia ATCC 17759 & PHB; $51.4 \%$ of CDW & {$[66]$} \\
\hline \multirow{3}{*}{ Whey lactose } & Haloferax mediterranei, & P-3(HB-co-8\%-HV); $50 \%$ of CDW & \multirow{3}{*}[67]{} \\
\hline & Pseudomonas hydrogenovora & PHB; $12 \%$ of CDW & \\
\hline & Hydrogenophaga pseudoflava & P-3(HB-co-5\%-HV); $40 \%$ of CDW & \\
\hline Biodiesel waste water & Novosphingobium sp. THA_AIK7 & PHB; $45 \%$ of CDW & {$[5]$} \\
\hline Oil palm frond juice & Cupriavidus necator CCUG52238 & PHB; $45 \pm 1.5$ wt $\%$ & {$[68]$} \\
\hline
\end{tabular}

D.J.G.B.D.S: deproteinized jowar grain based distillery spentwash, R.R.G.B.D.S: raw rice grain based distillery spentwash, F.F.P.I.W: filtered food processing industrial wastewater, PHD: polyhydroxydecanoate, H.S: hydrolyzed seed, H.G: hydrolyzed grass, 3Hx: (R)-3-hydroxyhexanoate, 3HO: (R)-3hydroxyoctanoate, 3HD: (R)-3-hydroxydecanoate, 3HDD: (R)-3-hydroxydodecanoate.

A linear corelation between monomer composition of PHA and mixture of saturated and unsaturated fatty acids has been elucidated in Pseudomonas putida GPol [156] and concept of PHA production as tailor made polymers was productively applicable, whereas polymer composition of PHA obtained from plant oils, glucose, and mixture of plant oils and glucose was dissimilar [157]. A study also reported that Pseudomonas putida and Pseudomonas aeruginosa as two different biological systems reflected differences between PHA synthase substrate specificity and route of PHA metabolic biosynthesis [158]. Plant oil and fats rich in different fatty acids when used as substrate have complex relation with respect to monomer composition of PHA formed and demand challenging research for PHA production as tailor made polymers [158].

3.2. Organic Loading Rate and Acids. Reports suggest that the increase in organic load is in direct relation to increase in PHB accumulation $[159,160]$. High substrate availability (feast conditions) takes longer time to store maximum of $\mathrm{PHB}$. Fewer organic loads result in faster PHB production. PHA production aptitude depends on substrate concentration because stored $\mathrm{PHB}$ was significantly high at higher substrate loading rate equal to $40.3 \%$ of CDW [161].
At different organic loading rate of $2.91 \mathrm{~kg} \mathrm{COD} \mathrm{m}^{-1}$ day, $3.54 \mathrm{~kg} \mathrm{COD} \mathrm{m}^{-3}$ day, $4.58 \mathrm{~kg} \mathrm{COD} \mathrm{m}^{-3}$ day, and $7.53 \mathrm{~kg}$ $\mathrm{COD} \mathrm{m}^{-3}$ day, PHA production was $25 \%, 15 \%, 8.5 \%$, and $6 \%$, respectively. Result obtained showed that maximum productivity was obtained with low substrate loading rate [153]. Effect of organic loading rate of synthetic acid and acidogenic effluent, namely, OLR1, OLR2, OLR3, and OLR4 (kg COD m ${ }^{-3}$ day), on PHA production and composition was evaluated in Pseudomonas otitidis. Synthetic acids (composed of acetate, propionic, and butyric acids) concentration varied for all different organic loading rates and acidogenic effluents had $\mathrm{pH}$ of 4.2 , VFA at $9.85 \mathrm{~g} \mathrm{~L}^{-1}, \mathrm{COD}$ of $24.52 \mathrm{~g} \mathrm{~L}^{-1}$, and carbohydrate at $13.75 \mathrm{~g} \mathrm{~L}^{-1}$. With increase in value of OLR from OLR1 to ORL4, time taken for maximum production also increased. Highest PHA accumulation was observed with ORL 2 followed by ORL3 then ORL1 and last ORL4. With ORL4, cells experienced sudden shock load of concentrated acids which led to impeded growth and less PHA production. From AE, similar trend was followed in respect to time but ORL3 showed maximum accumulation followed by ORL4, then ORL2, and last ORL1 [25]. Effect of high organic load from 8.5 to $31.25 \mathrm{~g} \mathrm{COD} \mathrm{L}^{-1}$ day on PHA production by mixed culture in SBR has been studied and concluded that OLR of $20 \mathrm{~g} \mathrm{COD} \mathrm{L}^{-1}$ day showed the best performance 
in regard to biomass productivity and storage capacity and further Alcaligenes, Thauera, and Comamonas genera spp. were reported as PHA producers based on DGGE [162].

3.3. $p H$. $\mathrm{pH}$ is also a very important factor in relation to PHA productivity and its monomer composition. Study on effect of $\mathrm{pH}$ on acidogenic fermentation shows that initial alkaline $\mathrm{pH}$ of 9 can generate good amount of VFAs [163]. Study on pH range also revealed that it affected composition of polymer formed in batch fermentation in respect to HV contents. PHA accumulated by mixed culture was higher in HV monomers when shifted from SBR maintained at $\mathrm{pH} 8.5$ to batch reactors maintained at $\mathrm{pH} 9.5$ without any decrease in PHA produced. They suggested that microorganisms maintain cytoplasmatic $\mathrm{pH}$ compatible with optimal cell functioning in response to change increase in $\mathrm{pH}$ of external environment. HV content of PHA produced increased from $10 \%$ to $30 \%$ mol with increase in $\mathrm{pH}$ from 5.5 to 9.5, respectively [41]. Operational condition at neutral redox condition $(\mathrm{pH} 7)$ resulted in PHB accumulation up to $25 \%$ of CDW when compared to basic pH $9(8.5 \%)$ and acidic pH 6 (15\%) [153]. Acetic acid and propionic acid mixture in different proportion was used as carbon substrate to enrich the culture with organic load of $8.5 \mathrm{~g} \mathrm{COD} \mathrm{L}^{-1}$ day maintained at $\mathrm{pH}$ ranging from 7.7 to 9.5. Enriched culture showed high production rate and yields (389 $\mathrm{mg} \mathrm{PHAg}^{-1}$ of nonpolymer biomass) in SBR if maintained at $\mathrm{pH}$ of 7.5 with Lampropedia hyalina as dominant bacterial species [164]. Different pretreatment methods applied to wastes, variables influencing selection of PHA producers in SBR, and PHA production reactor are shown in Figure 2.

3.4. Feeding Strategy. Production and composition of PHA varied with feeding strategy employed. Feeding regime affects the monomers compositions of PHA produced. Study by ${ }^{13} \mathrm{C}$ NMR spectroscopy showed that the chemical composition and microstructure of produced copolymer $\mathrm{P}(3 \mathrm{HB}-\mathrm{co}-\mathrm{HV})$ were significantly affected by feeding regime [165]. Feeding with acetate as carbon source under aerobic conditions in SBR showed no effect on microbial composition whereas substrate utilization rate was higher with pulse feeding mode than continuous feeding mode [166], whereas continuous feeding led to accumulation of PHA up to $64.5 \%$ in SBR by activated sludge collected from wastewater treatment plant and food wastes [163]. HV contents of PHA increased by $8 \%$ when fermented molasses as source of VFAs was fed continuously compared to pulsewise feeding strategy [22]. Increase by 4.8 -fold was reported when whey, a dairy waste product rich in sugars, as substrate was fed intermittently with ammonium sulfate in fed-batch culture of Methylobacterium sp. ZP24 under oxygen limiting conditions [167].

Periodic feeding (after every $2 \mathrm{hr}$ day $^{-1}$ ) of carbon substrate constituting acetic, propionic, and lactic acids at $8.5 \mathrm{~g} \mathrm{COD} \mathrm{L}^{-1} \mathrm{D}^{-1}$ resulted in production of co-polymer $\mathrm{P}(3 \mathrm{HB}-3 \mathrm{HV})$ and polymer (PHB) from activated sludge enriched by selective pressure in SBR [168]. The increase in OLR (up to $12.75 \mathrm{~g} \mathrm{COD} \mathrm{L}^{-1} \mathrm{D}^{-1}$ ) resulted in populations with high storage capacity and yields. Copolymer $\mathrm{P}(3 \mathrm{HB}-\mathrm{co}-$ $3 \mathrm{HV}$ ) with $18 \%$ of $\mathrm{HV}$ content was produced by periodically feeding the mixture of acetic, lactic, and propionic acids at frequency of $2 \mathrm{hr}$ with dilution rate of 1 day $^{-1}$. A Methylobacteriaceace bacterium, Flavobacterium sp., 28 Candidatus Meganema perideroedes, and Thauera sp. were dominant genera obtained under provided conditions [41]. Culture of Cupriavidus necator DSM 545 when pulse fed with soybean oil, rich in fatty acids, produced PHB (81\%) on onset of growth limited conditions with exhaustion of $\mathrm{P}, \mathrm{Cu}, \mathrm{Ca}$, and Fe [169]. PHB production was enhanced in 2-stage fed-batch cultivation of Pseudomonas putida when pre-grown cells in glucose were transferred to medium containing octanoate under nitrogen- and oxygen-limiting conditions [170].

\section{PHA and Simultaneously Produced Metabolites}

4.1. PHA and Biosurfactants. Biosurfactants are amphiphilic compounds with polar and nonpolar heads, known for their interface surface tension reducing capabilities and solubilization of aromatic compounds [171]. Biosurfactants commercialization is still a cost effective process. Biosurfactant production from different renewable substrates and fermentative aspects has been clearly discussed [88]. There is a metabolic resemblance between biosynthetic pathways of PHA and rhamnolipids. Rt1 is the enzyme which catalyses the reaction for formation of monorhamnolipids in Pseudomonas aeruginosa. It consists of two subunits RhlA and RhlB. RhlA subunit is responsible for $\beta$-hydroxy fatty acid dimer moiety formation. Rt1 can use both ACP-fatty acids and CoA-fatty acids for rhamnolipids formation. PHA is formed by polymerisation of $\beta$-hydroxy acids catalysed by enzyme PhaC, PHA synthase. Thus, PHA and rhamnolipids metabolic pathways compete for $\beta$-hydroxy-acids available in the vicinity. PhaG plays a significant role hereby in the formation of CoA-fatty acids from ACP-fatty acids followed by its conversion into polyhydroxyalkanoic acids [172].

Simultaneous production of PHA and rhamnolipids using decanoate as the most appropriate carbon source by Pseudomonas aeruginosa IF03924 has been studied. They were produced at stationary phase and there existed a time lag between the attainment of maximum production of PHA and rhamnolipids [33]. Later, it was reported that $\beta$ oxidation of fatty acids is rate-determining step for simultaneous production of PHA and rhamnolipids in Pseudomonas aeruginosa IF03924. The optimum temperatures for PHA and rhamnolipid syntheses were $30^{\circ} \mathrm{C}$ and $28^{\circ} \mathrm{C}$, respectively, suggesting that the product ratio between these two products can be controlled by changing temperature. Similarly, Pseudomonas aeruginosa IF03924 as inoculum and hydrolyzed palm oil as possible source of fatty acids and glycerol showed simultaneous production of PHA and rhamnolipids at the end of growth phase when nitrogen source gets exhausted [34]. In a similar investigation, Thermus thermophilus HB8 as inoculum and sunflower seed oil or oleic acid as substrate showed simultaneous production of PHA and rhamnolipids and also depicted that cells can be considered as "microbial 


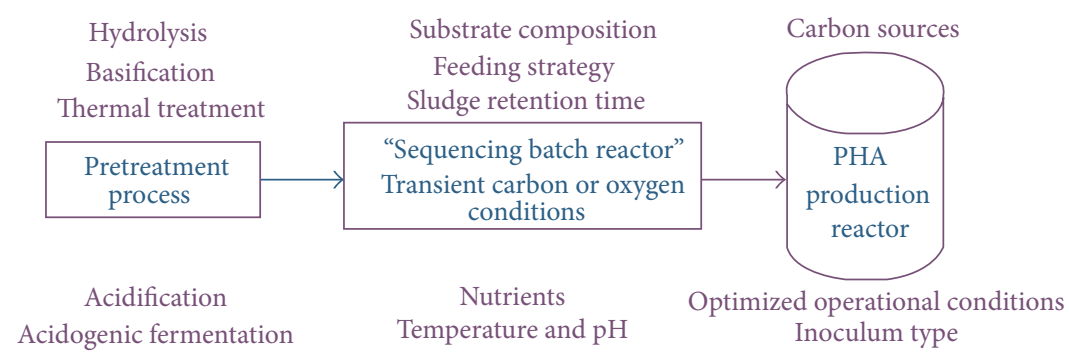

FIGURE 2: Different pretreatment methods applied to wastes, variables influencing selection of PHA producers in SBR, and PHA production reactor.

cell factories" to separate exoproducts (rhamnolipids) before disruption to recover stored intracellular inclusions (PHA) [173].

Both PHA and rhamnolipids, produced by Pseudomonas sp. have profound application in industries in reference to its eco-friendly properties but economy of individual production at large scale limits its applicability. Rhamnolipids and PHA could be separated using conventional techniques as discussed [33]. The use of nonpathogenic strains of Pseudomonas sp. to simultaneously produce rhamnolipids and PHAs using renewable resources can be helpful towards reducing the cost of overall production [174].

4.2. PHA and Extracellular Polymeric Substances. Extracellular polymeric substances protect and supply energy to cells when subjected to unfavourable growth conditions. Basically it is mixture of high molecular polymers which serve as supplier of carbon units when substrate is limited. As reported, EPS an extracellular product and PHB an intracellular product both are produced when organisms are under starvation conditions [37]. Simultaneous production of EPS and PHB was reported in Ralstonia eutropha ATCC 17699 [37], Azotobacter beijerinckii WDN-01 [175], and Anabaena cylindrica $10 \mathrm{C}$ [176]. Positive and negative effects of nitrogen concentration on EPS production were also reported $[37,176]$. EPS production was initiated in nitrogen-limiting conditions with fructose and glucose as efficient carbon sources in Azotobacter chroococcum [36], whereas increase in supply of nitrogen and glucose enhanced EPS production by Ralstonia eutropha ATCC 17699 in batch cultures [37]. Decomposition of EPS served as nitrogen source for PHB synthesis. On the other hand, $\mathrm{PHB}$ decomposition served as supplier of carbon units when external carbon source gets depleted [94].

Pseudomonas mendocina NK-01 produced simultaneously alginate oligosaccharides extracellularly and $\mathrm{mcl}$-PHAs intracellularly using glucose as main carbon source. Glycolysis converts glucose to acetyl-CoA which either enters into TCA cycle or gets converted into PHA. Acetyl-Co-A via TCA cycle is converted to oxaloacetate and then to fructose6-phosphate via gluconeogenesis. Fructose-6-phosphate is converted to mannose 6-phosphate and then subsequently to alginate oligosaccharide [35]. A diagrammatic representation of simultaneous production of extracellular and intracellular products is shown in Figure 3.

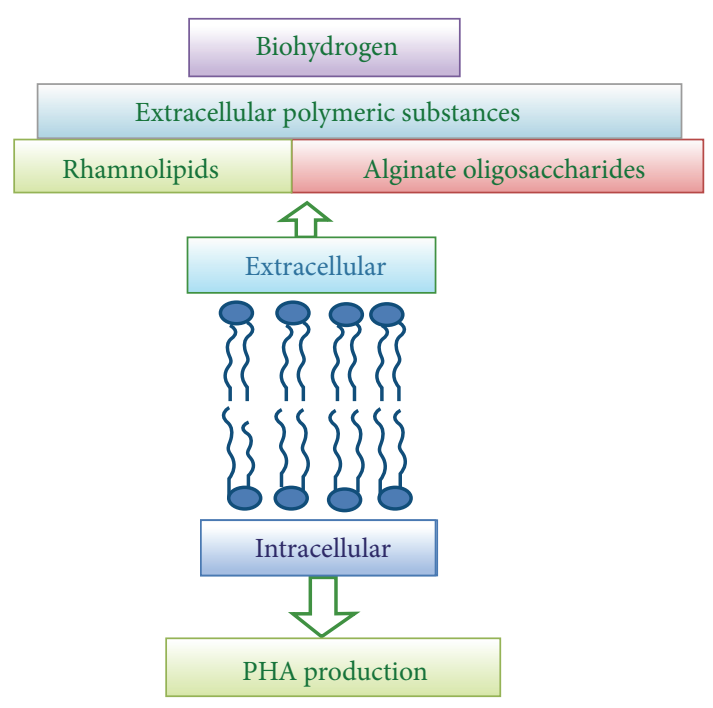

FIgURE 3: A diagrammatic representation of simultaneous production of extracellular and intracellular products.

4.3. PHA and Biohydrogen. Biological production of $\mathrm{H}_{2}$ gas is a promising technology attributed to its purity and less energy requirements [177]. Many purple nonsulfur bacteria like Rhodobacter sphaeroides, Rhodospirillum rubrum, Rhodopseudomonas palustris WP3-5, Rhodopseudomonas palustris $420 \mathrm{~L}$, and Bacillus sp. are reported to produce $\mathrm{H}_{2}$ and PHA under nutrient-limited conditions [38, 39, 178]. The literature shows that although PHB synthesis does compete with $\mathrm{H}_{2}$ production in $R$. palustris WP3-5, it is still conducive to $\mathrm{H}_{2}$ production when strain WP3-5 is in a stressful condition [39]. $\mathrm{H}_{2}$ gas production occurred at first stage (nitrogen-limited) and subsequent transfer of culture to second stage (phosphorus-limited) where PHB production takes place and it could be efficient light-dependent process to reduce the cost of bioproducts [178]. Some nonphotosynthetic bacterium like Bacillus thuringiensis UGU45 and Bacillus cereus EGU44 produced $\mathrm{H}_{2}$ gas in range of 1.67 to $1.92 \mathrm{~mol}$ $\mathrm{H}_{2}$ mol $^{-1}$ glucose ${ }^{-1}$ and $11.5 \%$ of CDW of PHB when grown on glucose in two-stage systems [38]. A study reported that stored PHB facilitated Rhodopseudomonas palustris WP3-5 bacterium to retain its $\mathrm{H}_{2}$ producing ability at optimum $\mathrm{pH}$ when subjected to extra environmental stress conditions like suboptimal $\mathrm{pH}$ value [39]. Integration of effluent generated 
from biohydrogen producing reactor serving as primary substrate for PHB production under anoxic conditions by aerobic consortia can be effective and efficient process [153].

\section{Discussion}

Hereby we have discussed how different types of physiological stress or ecological conditions could stimulate the PHA production in microbes as to survive and reproduce. Carbon and nutrients content of wastes vary depending on the point sources. Coupling of waste effluents or solid organic matter to acidogenic fermentation results in generation of VFAs. Anaerobic fermentation of olive oil mill effluents increased the percentage of VFAs from $18 \%$ to $32 \%$. Also, the concentration of produced PHA increased linearly with increase in concentration of substrate fed [114]. With control on $\mathrm{pH}$, different composition of VFAs could be obtained after acidogenic fermentation of palm oil mill effluents [179]. This can be more pronounced if hydraulic retention time (HRT) is kept for longer duration. Research on effect of HRT on acidogenic fermentation of dephenolized olive mill wastewater showed that 5 days of HRT could result in maximum conversion of COD into VFAs, that is, $78 \%$ of effluent COD [180].

PHA accumulating population varies with type of substrate being fed and substrate uptake capabilities of the microbial population. Butyrate and acetate were preferably taken up by Azoarcus and Thauera and broad range of substrates were taken up by Paracoccus [42]. PHB long-standing famine phase results in selection of those accumulating good amount of PHB [181]. It had been elucidated that, irrespective of sludges origin, PHA production was significantly dependent on operational sludge retention time [182]. Sludge retention time of 5 to 10 days showed maximum PHA production [141]. Sufficient supply of oxygen shifts cellular activities towards protein, glycogen, and other metabolic activities and thus inhibits PHA production because of availability of $\mathrm{ATP}$ and $\mathrm{NAD}^{+}$reducing equivalents, thereby necessitating proper oxygen management $[23,183]$. PHB produced under anoxic condition was higher than under aerobic conditions [116]. Two hours of aeration was very effective towards PHA production [141]. Thus, all together various biotic and abiotic variables interact with each other and result in effective PHA production with varying composition in SBR.

Concluding, it had been observed that number of bacterial genera are actively involved in PHA accumulation with silent features of degrading hydrocarbon, dyes, exhibiting PGPR traits, accumulating glycogen and polyphosphate, synthesising antibiotics, inhabiting high or low salts, and synthesis of food using sunlight as energy source. PHA production and simultaneous degradation of toxic effluents from industries can be effective towards sustainable development. Evaluating the capabilities of archaea tendency to grow under salty conditions with no stringent and nonsterilized conditions suggests a cost effective process. Salts in the sludges can be recycled to solve or minimize entrenched ecological problem related to postfermentation residues disposal. Thus, use of extremophiles biomass seems to develop attractive option to produce metabolites at commercial scale [184].

Organisms reported for simultaneous production of endopolymers and exopolymers are seemingly promising. Rhamnolipids and PHA are produced simultaneously by some Pseudomonas sp. and have common steps in respect to their metabolic biosynthesis [174]. Biosurfactants and PHA can be produced using broad range of substrate and organic wastes [24, 88]. Similarly, extracellular polymeric substances and biohydrogen gas [37] were reported to be produced simultaneously with PHA as discussed earlier in this paper. Thus, with proper understanding of ecological niches of strain of interest, future research should be towards use of wastes as renewable substrates, organisms with possibilities of simultaneously producing other metabolites as inocula, and subsequent production under well-optimized conditions in either batch or continuous production system.

\section{Conclusion}

PHA, a biodegradable stored substance of microbes, is alternative to petroleum-derived plastics. A technology needs serious remarks to develop an integrated system for separation of high-valued microbial synthesised products in concern with reduced cost production. Under environmental stress with excess of carbon available some microbes reportedly produce PHA intracellularly with simultaneous production of other metabolites. PHA production growth kinetics showed it to be produced at stationary phase in most of reported cases. These significantly important biologically produced by-products demand a vigorous establishment of industrial process contributing as key element towards high-cost production. The advent research on simultaneous production of polymeric substances (intracellularly as well as extracellularly) opens the door to new aspects of understanding the metabolic links and ecological prospects (i.e., defining role, diversity, and evolution). To have this high-valued endopolymers and exopolymers simultaneously produced using the same organisms under optimized conditions using domestic, industrial, agricultural, or industrial effluents waste may help us to combat the issues related to environmental pollution, cost production, and its commercialization into the market as well. Thus, we can have a real question to our mind: if waste is really "waste" in relation to production of high value products from its residing microbes.

\section{Objectives}

The main objectives of the review are

(1) comprehensive discussion on main producers of PHA and their ecological niches,

(2) to have idea about the main factors which affect the PHA production and composition,

(3) understanding of PHA and simultaneous production of metabolites. 


\section{Highlights}

The highlights of paper are

(i) comprehensive summary of PHA producers and their ecological niches,

(ii) discussion on main factors which affect the PHA production and composition,

(iii) biological processes of PHA and simultaneous production of metabolites using wastewaters as alternative resources.

\section{Conflict of Interests}

The authors declare that there is no conflict of interests.

\section{Acknowledgments}

The grant obtained from Department of Science and Technology (DST), Government of India and Haryana State Council for Science and Technology (HSCST) in the form of Major Research Project to Dr. Baljeet Singh Saharan (Principal Investigator), is fully acknowledged. The authors are also thankful to Kurukshetra University, Kurukshetra, India and Washington State University, Pullman, WA, USA, for providing necessary facilities for the research work.

\section{References}

[1] M. Koller, I. Gasser, F. Schmid, and G. Berg, "Linking ecology with economy: insights into polyhydroxyalkanoate-producing microorganisms," Engineering in Life Sciences, vol. 11, no. 3, pp. 222-237, 2011.

[2] D. P. Tamboli, A. N. Kagalkar, M. U. Jadhav, J. P. Jadhav, and S. P. Govindwar, "Production of polyhydroxyhexadecanoic acid by using waste biomass of Sphingobacterium sp. ATM generated after degradation of textile dye Direct Red 5B," Bioresource Technology, vol. 101, no. 7, pp. 2421-2427, 2010.

[3] J. Dalal, P. M. Sarma, M. Lavania, A. K. Mandal, and B. Lal, "Evaluation of bacterial strains isolated from oil-contaminated soil for production of polyhydroxyalkanoic acids (PHA)," Pedobiologia, vol. 54, no. 1, pp. 25-30, 2010.

[4] D. P. Tamboli, M. B. Kurade, T. R. Waghmode, S. M. Joshi, and S. P. Govindwar, "Exploring the ability of Sphingobacterium sp. ATM to degrade textile dye Direct Blue GLL, mixture of dyes and textile effluent and production of polyhydroxyhexadecanoic acid using waste biomass generated after dye degradation," Journal of Hazardous Materials, vol. 182, no. 1-3, pp. 169-176, 2010.

[5] J. Teeka, T. Imai, A. Reungsang et al., "Characterization of polyhydroxyalkanoates (PHAs) biosynthesis by isolated Novosphingobium sp. THA_AIK7 using crude glycerol," Journal of Industrial Microbiology and Biotechnology, vol. 39, no. 5, pp. 749-758, 2012.

[6] B. S. Saharan and P. Ranga, "Enhanced decolourization of congo red dye under submerged fermentation (SMF) process by newly isolated Bacillus subtilis $\mathrm{SPR}_{42}$," Journal of Applied and Natural Science, vol. 3, no. 1, pp. 51-53, 2010.

[7] B. S. Saharan and P. Ranga, "Optimization of cultural conditions for decolourization of textile azo dyes by Bacillus subtilis
$\mathrm{SPR}_{42}$ under submerged fermentation," International Journal of Advanced Biotechnology and Research, vol. 2, no. 1, pp. 148-153, 2011.

[8] B. S. Saharan, Ankita, and D. Sharma, "Detoxification and decolourization of textile mill effluent using autochthonous novel alkalophillic Microbacterium oxydans," in Proceedings of International Conference on Mycology and Plant Pathology: Biotechnological approaches, p. 53, Centre of advanced study in Botany, Banaras Hindu University, Varanasi, India, February 2012.

[9] A. R. Santal, N. P. Singh, and B. S. Saharan, "Biodegradation and detoxification of melanoidin from distillery effluent using an aerobic bacterial strain $\mathrm{SAG}_{5}$ of Alcaligenes faecalis," Journal of Hazardous Materials, vol. 193, pp. 319-324, 2011.

[10] F. Bosco and F. Chiampo, "Production of polyhydroxyalcanoates (PHAs) using milk whey and dairy wastewater activated sludge. Production of bioplastics using dairy residues," Journal of Bioscience and Bioengineering, vol. 109, no. 4, pp. 418421,2010

[11] P. Chakravarty, V. Mhaisalkar, and T. Chakrabarti, "Study on poly-hydroxyalkanoate (PHA) production in pilot scale continuous mode wastewater treatment system," Bioresource Technology, vol. 101, no. 8, pp. 2896-2899, 2010.

[12] S. RamKumar Pandian, V. Deepak, K. Kalishwaralal, N. Rameshkumar, M. Jeyaraj, and S. Gurunathan, "Optimization and fed-batch production of PHB utilizing dairy waste and sea water as nutrient sources by Bacillus megaterium SRKP-3," Bioresource Technology, vol. 101, no. 2, pp. 705-711, 2010.

[13] M. A. Hassan, L. N. Yee, P. L. Yee et al., "Sustainable production of polyhydroxyalkanoates from renewable oil-palm biomass," Biomass and Bioenergy, vol. 50, pp. 1-9, 2013.

[14] J. Yu, "Production of PHA from starchy wastewater via organic acids," Journal of Biotechnology, vol. 86, no. 2, pp. 105-112, 2001.

[15] M. G. E. Albuquerque, M. Eiroa, C. Torres, B. R. Nunes, and M. A. M. Reis, "Strategies for the development of a side stream process for polyhydroxyalkanoate (PHA) production from sugar cane molasses," Journal of Biotechnology, vol. 130, no. 4, pp. 411-421, 2007.

[16] S. Bengtsson, J. Hallquist, A. Werker, and T. Welander, "Acidogenic fermentation of industrial wastewaters: effects of chemostat retention time and $\mathrm{pH}$ on volatile fatty acids production," Biochemical Engineering Journal, vol. 40, no. 3, pp. 492-499, 2008.

[17] K. H. Kettl, K. Shahzad, M. Eder, and M. Narodoslawsky, "Ecological footprint comparison of biobased PHA production from animal residues," Chemical Engineering, vol. 29, 2012.

[18] J. M. Naranjo, J. A. Posada, J. C. Higuita, and C. A. Cardona, "Valorization of glycerol through the production of biopolymers: the PHB case using Bacillus megaterium," Bioresource Technology, vol. 133, pp. 38-44, 2013.

[19] A. A. Khardenavis, M. Suresh Kumar, S. N. Mudliar, and T. Chakrabarti, "Biotechnological conversion of agroindustrial wastewaters into biodegradable plastic, poly $\beta$-hydroxybutyrate," Bioresource Technology, vol. 98, no. 18, pp. 3579-3584, 2007.

[20] M. A. M. Reis, L. S. Serafim, P. C. Lemos, A. M. Ramos, F. R. Aguiar, and M. C. M. van Loosdrecht, "Production of polyhydroxyalkanoates by mixed microbial cultures," Bioprocess and Biosystems Engineering, vol. 25, no. 6, pp. 377-385, 2003. 
[21] A. J. Anderson and E. A. Dawes, "Occurrence, metabolism, metabolic role, and industrial uses of bacterial polyhydroxyalkanoates," Microbiological Reviews, vol. 54, no. 4, pp. 450472,1990

[22] M. G. E. Albuquerque, V. Martino, E. Pollet, L. Avérous, and M. A. M. Reis, "Mixed culture polyhydroxyalkanoate (PHA) production from volatile fatty acid (VFA)-rich streams: effect of substrate composition and feeding regime on PHA productivity, composition and properties," Journal of Biotechnology, vol. 151, no. 1, pp. 66-76, 2011.

[23] H. Salehizadeh and M. C. M. van Loosdrecht, "Production of polyhydroxyalkanoates by mixed culture: recent trends and biotechnological importance," Biotechnology Advances, vol. 22, no. 3, pp. 261-279, 2004.

[24] L. S. Serafim, P. C. Lemos, M. G. E. Albuquerque, and M. A. M. Reis, "Strategies for PHA production by mixed cultures and renewable waste materials," Applied Microbiology and Biotechnology, vol. 81, no. 4, pp. 615-628, 2008.

[25] M. V. Reddy, G. N. Nikhil, S. V. Mohan, Y. V. Swamy, and P. N. Sarma, "Pseudomonas otitidis as a potential biocatalyst for polyhydroxyalkanoates (PHA) synthesis using synthetic wastewater and acidogenic effluents," Bioresource Technology, vol. 123, pp. 471-479, 2012.

[26] P. C. Lemos, C. Viana, E. N. Salgueiro, A. M. Ramos, J. P. S. G. Crespo, and M. A. M. Reis, "Effect of carbon source on the formation of polyhydroxyalkanoates (PHA) by a phosphateaccumulating mixed culture," Enzyme and Microbial Technology, vol. 22, no. 8, pp. 662-671, 1998.

[27] A. Akar, E. U. Akkaya, S. K. Yesiladali et al., "Accumulation of polyhydroxyalkanoates by Microlunatus phosphovorus under various growth conditions," Journal of Industrial Microbiology and Biotechnology, vol. 33, no. 3, pp. 215-220, 2006.

[28] S. Bengtsson, A. R. Pisco, P. Johansson, P. C. Lemos, and M. A. M. Reis, "Molecular weight and thermal properties of polyhydroxyalkanoates produced from fermented sugar molasses by open mixed cultures," Journal of biotechnology, vol. 147, no. 3-4, pp. 172-179, 2010.

[29] A. Pramanik, A. Mitra, M. Arumugam et al., "Utilization of vinasse for the production of polyhydroxybutyrate by Haloarcula marismortui," Folia Microbiologica, vol. 57, no. 1, pp. 71-79, 2012.

[30] N. I. López, J. A. Ruiz, and B. S. Méndez, "Survival of poly3-hydroxybutyrate-producing bacteria in soil microcosms," World Journal of Microbiology and Biotechnology, vol. 14, no. 5, pp. 681-684, 1998.

[31] Y. H. Zhao, H. M. Li, L. F. Qin, H. H. Wang, and G.-Q. Chen, "Disruption of the polyhydroxyalkanoate synthase gene in Aeromonas hydrophila reduces its survival ability under stress conditions," FEMS Microbiology Letters, vol. 276, no. 1, pp. 3441, 2007.

[32] A. López-Cortés, A. Lanz-Landázuri, and J. Q. GarcíaMaldonado, "Screening and Isolation of PHB-Producing Bacteria in a Polluted Marine Microbial Mat," Microbial Ecology, vol. 56, no. 1, pp. 112-120, 2008.

[33] K. Hori, S. Marsudi, and H. Unno, "Simultaneous production of polyhydroxyalkanoates and rhamnolipids by Pseudomonas aeruginosa," Biotechnology and Bioengineering, vol. 78, no. 6, pp. 699-707, 2002.

[34] S. Marsudi, H. Unno, and K. Hori, "Palm oil utilization for the simultaneous production of polyhydroxyalkanoates and rhamnolipids by Pseudomonas aeruginosa," Applied Microbiology and Biotechnology, vol. 78, no. 6, pp. 955-961, 2008.
[35] W. Guo, C. Song, M. Kong, W. Geng, Y. Wang, and S. Wang, "Simultaneous production and characterization of mediumchain-length polyhydroxyalkanoates and alginate oligosaccharides by Pseudomonas mendocina NK-01," Applied Microbiology and Biotechnology, vol. 92, no. 4, pp. 791-801, 2011.

[36] J. C. Quagliano and S. S. Miyazaki, "Biosynthesis of poly$\beta$-hydroxybutyrate and exopolysaccharides on Azotobacter chroococcum strain 6B utilizing simple and complex carbon sources," Applied Biochemistry and Biotechnology A, vol. 82, no. 3, pp. 199-208, 1999.

[37] J. Wang and H.-Q. Yu, "Biosynthesis of polyhydroxybutyrate (PHB) and extracellular polymeric substances (EPS) by Ralstonia eutropha ATCC 17699 in batch cultures," Applied Microbiology and Biotechnology, vol. 75, no. 4, pp. 871-878, 2007.

[38] S. K. S. Patel, M. Singh, and V. C. Kalia, "Hydrogen and polyhydroxybutyrate producing abilities of Bacillus spp. From glucose in two stage system," Indian Journal of Microbiology, vol. 51, no. 4, pp. 418-423, 2011.

[39] S. C. Wu, S. Z. Liou, and C. M. Lee, "Correlation between bio-hydrogen production and polyhydroxybutyrate (PHB) synthesis by Rhodopseudomonas palustris WP3-5," Bioresource Technology, vol. 113, pp. 44-50, 2012.

[40] A. S. M. Chua, H. Takabatake, H. Satoh, and T. Mino, "Production of polyhydroxyalkanoates (PHA) by activated sludge treating municipal wastewater: effect of $\mathrm{pH}$, sludge retention time (SRT), and acetate concentration in influent," Water Research, vol. 37, no. 15, pp. 3602-3611, 2003.

[41] D. Dionisi, M. Beccari, S. D. Gregorio, M. Majone, M. P. Papini, and G. Vallini, "Storage of biodegradable polymers by an enriched microbial community in a sequencing batch reactor operated at high organic load rate," Journal of Chemical Technology and Biotechnology, vol. 80, no. 11, pp. 1306-1318, 2005.

[42] M. G. E. Albuquerque, G. Carvalho, C. Kragelund et al., "Link between microbial composition and carbon substrate-uptake preferences in a PHA-storing community," The ISME Journal, vol. 7, no. 1, pp. 1-12, 2013.

[43] C. D. M. Filipe, G. T. Daigger, and C. P. L. Grady Jr., "A metabolic model for acetate uptake under anaerobic conditions by glycogen accumulating organisms: stoichiometry, kinetics, and the effect of $\mathrm{pH}$, "Biotechnology and Bioengineering, vol. 76, no. 1, pp. 17-31, 2001.

[44] Y. Jiang, L. Marang, R. Kleerebezem, G. Muyzer, and M. C. M. van Loosdrecht, "Effect of temperature and cycle length on microbial competition in PHB-producing sequencing batch reactor," The ISME Journal, vol. 5, no. 5, pp. 896-907, 2011.

[45] G. Eggink, International Symposium on Bacterial Polyhydroxyalkanoates, National Research Council of Canada, 1997.

[46] R. M. Atlas, "Petroleum biodegradation and oil spill bioremediation," Marine Pollution Bulletin, vol. 31, no. 4-12, pp. 178-182, 1995.

[47] T. Maskow and W. Babel, "Calorimetrically recognized maximum yield of poly-3-hydroxybutyrate (PHB) continuously synthesized from toxic substrates," Journal of Biotechnology, vol. 77, no. 2-3, pp. 247-253, 2000.

[48] F. Masood, F. Hasan, S. Ahmed, and A. Hameed, "Biosynthesis and characterization of poly(3-hydroxybutyrate-co-3hydroxyvalerate) from Bacillus cereus FAll isolated from TNTcontaminated soil," Annals of Microbiology, vol. 62, no. 4, pp. 1377-1384, 2012.

[49] J. S. Sabirova, M. Ferrer, H. Lünsdorf et al., "Mutation in a "tesB-like" hydroxyacyl-coenzyme A-specific thioesterase gene 
causes hyperproduction of extracellular polyhydroxyalkanoates by Alcanivorax borkumensis SK2," Journal of Bacteriology, vol. 188, no. 24, pp. 8452-8459, 2006.

[50] K. Hori, M. Abe, and H. Unno, "Production of triacylglycerol and poly(3-hydroxybutyrate-co-3-hydroxyvalerate) by the toluene-degrading bacterium Rhodococcus aetherivorans IAR1," Journal of Bioscience and Bioengineering, vol. 108, no. 4, pp. 319324, 2009.

[51] Y.-Y. Ni, D. Y. Kim, M. G. Chung, S. H. Lee, H.-Y. Park, and Y. H. Rhee, "Biosynthesis of medium-chain-length poly(3-hydroxyalkanoates) by volatile aromatic hydrocarbonsdegrading Pseudomonas fulva TY16," Bioresource Technology, vol. 101, no. 21, pp. 8485-8488, 2010.

[52] S. Sangyoka, "Optimum conditions for the production of polyhydroxybutyrate from cassava wastewater by the newly isolated Cupriavidus sp. KKU38," Sains Malaysiana, vol. 41, no. 10, pp. 1211-1216, 2012.

[53] A. D. Tripathi, A. Yadav, A. Jha, and S. K. Srivastava, "Utilizing of sugar refinery waste (cane molasses) for production of bio-plastic under submerged fermentation process," Journal of Polymers and the Environment, vol. 20, no. 2, pp. 446-453, 2012.

[54] A. Jeyaseelan, S. Pandiyan, and P. Ravi, "Production of polyhydroxyalkanoate (PHA) using hydrolyzed grass and syzygium cumini seed as low cost substrates," Journal of Microbiology, Biotechnology and Food Sciences, vol. 2, no. 3, pp. 970-982, 2012.

[55] M. Aznury, A. Trianto, A. Pancoro, and T. Setiadi, "Effect of feeding time of volatile fatty acids from palm oil mill effluent on production of polyhydroxyalkanoates by ralstonia eutropha JMP 134 in batch fermentation," in Proceedings of 5th AUN/SEED Regional Conference on Global Environment, November 2012.

[56] R. Sindhu, N. Silviya, P. Binod, and A. Pandey, "Pentose-rich hydrolysate from acid pretreated rice straw as a carbon source for the production of poly-3-hydroxybutyrate," Biochemical Engineering Journal, vol. 78, pp. 67-72, 2013.

[57] A. D. Allen, W. A. Anderson, F. O. Ayorinde, and B. E. Eribo, "Biosynthesis and characterization of copolymer poly $(3 \mathrm{HB}-$ co-3HV) from saponified Jatropha curcas oil by Pseudomonas oleovorans," Journal of Industrial Microbiology and Biotechnology, vol. 37, no. 8, pp. 849-856, 2010.

[58] L. F. Silva, M. K. Taciro, M. E. Michelin Ramos, J. M. Carter, J. G. C. Pradella, and J. G. C. Gomez, "Poly-3-hydroxybutyrate (P3HB) production by bacteria from xylose, glucose and sugarcane bagasse hydrolysate," Journal of Industrial Microbiology and Biotechnology, vol. 31, no. 6, pp. 245-254, 2004.

[59] A. Bhattacharyya, A. Pramanik, S. K. Maji, S. Haldar, U. K. Mukhopadhyay, and J. Mukherjee, "Utilization of vinasse for production of poly-3-(hydroxybutyrate-co-hydroxyvalerate) by Haloferax mediterranei," AMB Express, vol. 2, article 34, 2012.

[60] S. G. V. A. O. Costa, F. Lépine, S. Milot, E. Déziel, M. Nitschke, and J. Contiero, "Cassava wastewater as a substrate for the simultaneous production of rhamnolipids and polyhydroxyalkanoates by pseudomonas aeruginosa," Journal of Industrial Microbiology and Biotechnology, vol. 36, no. 8, pp. 1063-1072, 2009.

[61] A. Yezza, A. Halasz, W. Levadoux, and J. Hawari, "Production of poly- $\beta$-hydroxybutyrate (PHB) by Alcaligenes latus from maple sap," Applied Microbiology and Biotechnology, vol. 77, no. 2, pp. 269-274, 2007.
[62] N. Ceyhan and G. Ozdemir, "Poly- $\beta$-hydroxybutyrate (PHB) production from domestic wastewater using Enterobacter aerogenes 12Bi strain," African Journal of Microbiology Research, vol. 5, no. 6, pp. 690-702, 2011.

[63] S. Povolo, M. G. Romanelli, F. Fontana, M. Basaglia, and S. Casella, "Production of polyhydroxyalkanoates from fatty wastes," Journal of Polymer Environment, vol. 20, no. 4, pp. 944949, 2012.

[64] H. Ramachandran and A. A. Amirul, "Yellow-pigmented Cupriavidus sp., a novel bacterium capable of utilizing glycerine pitch for the sustainable production of $\mathrm{P}(3 \mathrm{HB}-$ co-4HB)," Journal of Chemical Technology and Biotechnology, vol. 88, no. 6, pp. 10301038, 2013.

[65] R. Haas, B. Jin, and F. T. Zepf, "Production of poly(3hydroxybutyrate) from waste potato starch," Bioscience, Biotechnology and Biochemistry, vol. 72, no. 1, pp. 253-256, 2008.

[66] W. Pan, J. A. Perrotta, A. J. Stipanovic, C. T. Nomura, and J. P. Nakas, "Production of polyhydroxyalkanoates by Burkholderia cepacia ATCC 17759 using a detoxified sugar maple hemicellulosic hydrolysate," Journal of Industrial Microbiology and Biotechnology, vol. 39, no. 9, pp. 459-469, 2012.

[67] M. Koller, P. Hesse, R. Bona, C. Kutschera, A. Atlić, and G. Braunegg, "Potential of various archae- and eubacterial strains as industrial polyhydroxyalkanoate producers from whey," Macromolecular Bioscience, vol. 7, no. 2, pp. 218-226, 2007.

[68] Zahari, M. A. K. M, H. Ariffin et al., "Factors affecting poly(3hydroxybutyrate) production from oil palm frond juice by Cupriavidus necator (CCUG52238 ${ }^{\mathrm{T}}$ )," Journal of Biomedicine and Biotechnology, vol. 2012, Article ID 125865, 8 pages, 2012.

[69] A. Oren, "Microbial life at high salt concentrations: phylogenetic and metabolic diversity," Saline Systems, vol. 4, article 2, 2008.

[70] R. G. Kirk and M. Ginzburg, "Ultrastructure of two species of halobacterium," Journal of Ultrasructure Research, vol. 41, no. 12, pp. 80-94, 1972.

[71] R. Fernandez-Castillo, F. Rodriguez-Valera, J. GonzalezRamos, and F. Ruiz-Berraquero, "Accumulation of $\operatorname{poly}(\beta-$ hydroxybutyrate) by Halobacteria," Applied and Environmental Microbiology, vol. 51, no. 1, pp. 214-216, 1986.

[72] J. Garcia Lillo and F. Rodriguez-Valera, "Effects of culture conditions on poly ( $\beta$-hydroxybutyrate acid) production by Haloferax mediterranei," Applied and Environmental Microbiology, vol. 56, no. 8, pp. 2517-2521, 1990.

[73] J. Quillaguamán, S. Hashim, F. Bento, B. Mattiasson, and R. Hatti-Kaul, "Poly( $\beta$-hydroxybutyrate) production by a moderate halophile, Halomonas boliviensis LC1 using starch hydrolysate as substrate," Journal of Applied Microbiology, vol. 99, no. 1, pp. 151-157, 2005.

[74] J. Quillaguamán, O. Delgado, B. Mattiasson, and R. Hatti-Kaul, "Poly( $\beta$-hydroxybutyrate) production by a moderate halophile, Halomonas boliviensis LC1," Enzyme and Microbial Technology, vol. 38, no. 1-2, pp. 148-154, 2006.

[75] F. F. Hezayen, M. C. Gutiérrez, A. Steinbüchel, B. J. Tindall, and B. H. A. Rehm, "Halopiger aswanensis sp. nov., a polymerproducing and extremely halophilic archaeon isolated from hypersaline soil," International Journal of Systematic and Evolutionary Microbiology, vol. 60, no. 3, pp. 633-637, 2010.

[76] J. Han, Q. Lu, L. Zhou, J. Zhou, and H. Xiang, "Molecular characterization of the phaECHm genes, required for biosynthesis of poly(3-hydroxybutyrate) in the extremely halophilic archaeon Haloarcula marismortui," Applied and Environmental Microbiology, vol. 73, no. 19, pp. 6058-6065, 2007. 
[77] A. Legat, C. Gruber, K. Zangger, G. Wanner, and H. StanLotter, "Identification of polyhydroxyalkanoates in Halococcus and other haloarchaeal species," Applied Microbiology and Biotechnology, vol. 87, no. 3, pp. 1119-1127, 2010.

[78] J. Quillaguamán, H. Guzmán, D. Van-Thuoc, and R. HattiKaul, "Synthesis and production of polyhydroxyalkanoates by halophiles: current potential and future prospects," Applied Microbiology and Biotechnology, vol. 85, no. 6, pp. 1687-1696, 2010.

[79] R. de Philippis, A. Ena, M. Guastini, C. Sili, and M. Vincenzini, "Factors affecting poly- $\beta$-hydroxybutyrate accumulation in cyanobacteria and in purple non-sulfur bacteria," FEMS Microbiology Reviews, vol. 103, no. 2-4, pp. 187-194, 1992.

[80] M. Nishioka, K. Nakai, M. Miyake, Y. Asada, and M. Taya, "Production of poly- $\beta$-hydroxybutyrate by thermophilic cyanobacterium, Synechococcus sp. MA19, under phosphate-limited conditions," Biotechnology Letters, vol. 23, no. 14, pp. 1095-1099, 2001.

[81] B. Panda, L. Sharma, and N. Mallick, "Poly- $\beta$-hydroxybutyrate accumulation in Nostoc muscorum and Spirulina platensis under phosphate limitation," Journal of Plant Physiology, vol. 162, no. 12, pp. 1376-1379, 2005.

[82] B. Panda, P. Jain, L. Sharma, and N. Mallick, "Optimization of cultural and nutritional conditions for accumulation of poly$\beta$-hydroxybutyrate in Synechocystis sp. PCC 6803," Bioresource Technology, vol. 97, no. 11, pp. 1296-1301, 2006.

[83] G. Wu, T. Boa, Z. Shen, and Q. Wu, "Sodium acetate stimulates PHB biosynthesis in Synechocystis sp. PCC, 6803," Tsinghua Science and Technology, vol. 7, no. 4, pp. 435-438, 2002.

[84] S. P. Yew, M. H. Sau, K. H. Yong, R. M. M. Abed, and K. Sudesh, "Morphological studies of Synechocystis sp. UNIWG under polyhrdroxyalkanoate accumulating conditions," Malaysian Journal of Microbiology, vol. 1, no. 1, pp. 48-52, 2005.

[85] B. Panda and N. Mallick, "Enhanced poly- $\beta$-hydroxybutyrate accumulation in a unicellular cyanobacterium, Synechocystis sp. PCC 6803," Letters in Applied Microbiology, vol. 44, no. 2, pp. 194-198, 2007.

[86] M. R. Melnicki, E. Eroglu, and A. Melis, "Changes in hydrogen production and polymer accumulation upon sulfur-deprivation in purple photosynthetic bacteria," International Journal of Hydrogen Energy, vol. 34, no. 15, pp. 6157-6170, 2009.

[87] L. Sharma and N. Mallick, "Enhancement of poly- $\beta$ hydroxybutyrate accumulation in Nostoc muscorum under mixotrophy, chemoheterotrophy and limitations of gasexchange," Biotechnology Letters, vol. 27, no. 1, pp. 59-62, 2005.

[88] B. S. Saharan, R. K. Sahu, and D. Sharma, "A review on biosurfactants: fermentation, current developments and perspectives," Genetic Engineering and Biotechnology Journal, vol. 2011, 2011.

[89] A. Rana, B. Saharan, M. Joshi, R. Prasanna, K. Kumar, and L. Nain, "Identification of multi-trait PGPR isolates and evaluating their potential as inoculants for wheat," Annals of Microbiology, vol. 61, no. 4, pp. 893-900, 2011.

[90] I. Gasser, H. Müller, and G. Berg, "Ecology and characterization of polyhydroxyalkanoate-producing microorganisms on and in plants," FEMS Microbiology Ecology, vol. 70, no. 1, pp. 142-150, 2009.

[91] D. Kadouri, S. Castro-Sowinski, E. Jurkevitch, and Y. Okon, "Ecological and agricultural significance of bacterial polyhydroxyalkanoates," Critical Reviews in Microbiology, vol. 31, no. 2, pp. 55-67, 2005.
[92] D. Kadouri, E. Jurkevitch, and Y. Okon, "Involvement of the reserve material poly- $\beta$-hydroxybutyrate in Azospirillum brasilense stress endurance and root colonization," Applied and Environmental Microbiology, vol. 69, no. 6, pp. 3244-3250, 2003.

[93] A. Tunlid, B. H. Baird, M. B. Trexler, S. Olsson, and R. H. Findlay, "Determination of phospholipid ester-linked fatty acids for the estimation of bacterial biomass and activity in the rhizosphere of the rape plant Brassica napus L," Canadian Journal of Microbiology, vol. 31, no. 12, pp. 1113-1119, 1985.

[94] J. G. Wang and L. R. Bakken, "Screening of soil bacteria for poly$\beta$-hydroxybutyric acid production and its role in the survival of starvation," Microbial Ecology, vol. 35, no. 1, pp. 94-101, 1998.

[95] T. C. S. de Lima, B. M. Grisi, and M. C. M. Bonato, "Bacteria isolated from a sugarcane agroecosystem: their potential production of polyhydroxyalcanoates and resistance to antibiotics," Revista de Microbiologia, vol. 30, no. 3, pp. 214-224, 1999.

[96] W. Reichardt, G. Mascariña, B. Padre, and J. Doll, "Microbial communities of continuously cropped, irrigated rice fields," Applied and Environmental Microbiology, vol. 63, no. 1, pp. 233238, 1997.

[97] D. M. R. Romo, M. V. Grosso, N. C. M. Solano, and D. M. Castaño, "A most effective method for selecting a broad range of short and medium-chain-length polyhidroxyalcanoate producing microorganisms," Electronic Journal of Biotechnology, vol. 10, no. 3, pp. 348-357, 2007.

[98] W. C. Ratcliff, S. V. Kadam, and R. F. Denison, "Poly-3hydroxybutyrate (PHB) supports survival and reproduction in starving rhizobia," FEMS Microbiology Ecology, vol. 65, no. 3, pp. 391-399, 2008.

[99] B. S. Saharan and P. Badoni, "Poly- $\beta$-hydroxy production using Azotobacter species from contaminated sites," Environment and Ecology, vol. 25, no. 3, pp. 737-740, 2007.

[100] P. J. Senior, G. A. Beech, G. A. Ritchie, and E. A. Dawes, "The role of oxygen limitation in the formation of poly3-hydroxybutyrate during batch and continuous culture of Azotobacter beijerinckii," Biochemical Journal, vol. 128, no. 5, pp. 1193-1201, 1972.

[101] H. Stam, H. W. van Verseveld, W. de Vries, and A. H. Stouthamer, "Utilization of poly- $\beta$-hydroxybutyrate in freeliving cultures of Rhizobium ORS571," FEMS Microbiology Letters, vol. 35, no. 2-3, pp. 215-220, 1986.

[102] H. Stockdale, D. W. Ribbons, and E. A. Dawes, "Occurrence of poly-beta-hydroxybutyrate in the Azotobacteriaceae," Journal of Bacteriology, vol. 95, no. 5, pp. 1798-1803, 1968.

[103] M. A. Trainer and T. C. Charles, "The role of PHB metabolism in the symbiosis of rhizobia with legumes," Applied Microbiology and Biotechnology, vol. 71, no. 4, pp. 377-386, 2006.

[104] S. Kumbhakar, P. K. Singh, and A. S. Vidyarthi, "Screening of root nodule bacteria for the production of polyhydroxyalkanoate (PHA) and the study of parameters influencing the PHA accumulation," African Journal of Biotechnology, vol. 11, no. 31, pp. 7934-7946, 2012.

[105] L. V. Kannan and Z. Rehacek, "Formation of poly-betahydroxybutyrate by Actinomycetes," Indian journal of biochemistry, vol. 7, no. 2, pp. 126-129, 1970.

[106] A. Manna, R. Banerjee, and A. K. Paul, "Accumulation of poly (3-hydroxybutyric acid) by some soil Streptomyces," Current Microbiology, vol. 39, no. 3, pp. 153-158, 1999.

[107] S. Verma, Y. Bhatia, S. P. Valappil, and I. Roy, "A possible role of poly-3-hydroxybutyric acid in antibiotic production in Streptomyces," Archives of Microbiology, vol. 179, no. 1, pp. 6669, 2003. 
[108] M. Raman Kutty, L. V. Kannan, and Z. Rehacek, "Effect of phosphate on biosynthesis of antimycin $A$ and production and utilization of poly-beta-hydroxybutyrate by Streptomyces antibioticus," Indian journal of biochemistry, vol. 6, no. 4, pp. 230-231, 1969.

[109] N. Ranada and L. C. Vining, "Accumulation of intracellular carbon reserves in relation to chloramphenicol biosynthesis by Streptomyces venezuelae," Canadian Journal of Microbiology, vol. 39, no. 4, pp. 377-383, 1993.

[110] K. Wu, L. Chung, W. P. Revill, L. Katz, and C. D. Reeves, "The FK520 gene cluster of Streptomyces hygroscopicus var. ascomyceticus (ATCC 14891) contains genes for biosynthesis of unusual polyketide extender units," Gene, vol. 251, no. 1, pp. 8190, 2000.

[111] S. P. Valappil, A. R. Boccaccini, C. Bucke, and I. Roy, "Polyhydroxyalkanoates in Gram-positive bacteria: insights from the genera Bacillus and Streptomyces," Antonie van Leeuwenhoek, vol. 91, no. 1, pp. 1-17, 2007.

[112] M. Beccari, D. Dionisi, A. Giuliani, M. Majone, and R. Ramadori, "Effect of different carbon sources on aerobic storage by activated sludge," Water Science and Technology, vol. 45, no. 6, pp. 157-168, 2002.

[113] K. Dircks, M. Henze, M. C. M. van Loosdrecht, H. Mosbæk, and H. Aspegren, "Storage and degradation of poly- $\beta$ hydroxybutyrate in activated sludge under aerobic conditions," Water Research, vol. 35, no. 9, pp. 2277-2285, 2001.

[114] M. Beccari, L. Bertin, D. Dionisi et al., "Exploiting olive oil mill effluents as a renewable resource for production of biodegradable polymers through a combined anaerobic-aerobic process," Journal of Chemical Technology and Biotechnology, vol. 84, no. 6, pp. 901-908, 2009.

[115] S. Bengtsson, A. Werker, M. Christensson, and T. Welander, "Production of polyhydroxyalkanoates by activated sludge treating a paper mill wastewater," Bioresource Technology, vol. 99, no. 3, pp. 509-516, 2008.

[116] M. Venkateswar Reddy and S. Venkata Mohan, "Influence of aerobic and anoxic microenvironments on polyhydroxyalkanoates (PHA) production from food waste and acidogenic effluents using aerobic consortia," Bioresource Technology, vol. 103, no. 1, pp. 313-321, 2012.

[117] L. L. Wallen and W. K. Rohwedder, "Poly- $\beta$-hydroxyalkanoate from activated sludge," Environmental Science and Technology, vol. 8, no. 6, pp. 576-579, 1974.

[118] M. C. M. van Loosdrecht, C. M. Hooijmans, D. Brdjanovic, and J. J. Heijnen, "Biological phosphate removal processes," Applied Microbiology and Biotechnology, vol. 48, no. 3, pp. 289-296, 1997.

[119] M. M. Santos, P. C. Lemos, M. A. M. Reis, and H. Santos, "Glucose metabolism and kinetics of phosphorus removal by the fermentative bacterium Microlunatus phosphovorus," Applied and Environmental Microbiology, vol. 65, no. 9, pp. 3920-3928, 1999.

[120] K. S. le Corre, E. Valsami-Jones, P. Hobbs, and S. A. Parsons, "Phosphorus recovery from wastewater by struvite crystallization: a review," Critical Reviews in Environmental Science and Technology, vol. 39, no. 6, pp. 433-477, 2009.

[121] S. Bengtsson, "The utilization of glycogen accumulating organisms for mixed culture production of polyhydroxyalkanoates," Biotechnology and Bioengineering, vol. 104, no. 4, pp. 698-708, 2009.

[122] R. G. Crocetti, J. F. Banfield, J. Keller, P. L. Bond, and L. L. Blackall, "Glycogen-accumulating organisms in laboratory-scale and full-scale wastewater treatment processes," Microbiology, vol. 148, no. 11, pp. 3353-3364, 2002.

[123] R. L. Meyer, A. M. Saunders, and L. L. Blackall, "Putative glycogen-accumulating organisms belonging to the Alphaproteobacteria identified through rRNA-based stable isotope probing," Microbiology, vol. 152, no. 2, pp. 419-429, 2006.

[124] M.-T. Wong, F. M. Tan, W. J. Ng, and W.-T. Liu, "Identification and occurrence of tetrad-forming Alphaproteobacteria in anaerobic-aerobic activated sludge processes," Microbiology, vol. 150, no. 11, pp. 3741-3748, 2004.

[125] A. R. Pisco, S. Bengtsson, A. Werker, M. A. M. Reis, and P. C. Lemos, "Community structure evolution and enrichment of glycogen-accumulating organisms producing polyhydroxyalkanoates from fermented molasses," Applied and Environmental Microbiology, vol. 75, no. 14, pp. 4676-4686, 2009.

[126] Y. Dai, L. Lambert, Z. Yuan, and J. Keller, "Microstructure of copolymers of polyhydroxyalkanoates produced by glycogen accumulating organisms with acetate as the sole carbon source," Process Biochemistry, vol. 43, no. 9, pp. 968-977, 2008.

[127] Y. Dai, Z. Yuan, X. Wang, A. Oehmen, and J. Keller, "Anaerobic metabolism of Defluviicoccus vanus related glycogen accumulating organisms (GAOs) with acetate and propionate as carbon sources," Water Research, vol. 41, no. 9, pp. 1885-1896, 2007.

[128] Y. Dai, Z. Yuan, K. Jack, and J. Keller, "Production of targeted poly(3-hydroxyalkanoates) copolymers by glycogen accumulating organisms using acetate as sole carbon source," Journal of Biotechnology, vol. 129, no. 3, pp. 489-497, 2007.

[129] S. Ciesielski, T. Pokoj, and E. Klimiuk, "Molecular insight into activated sludge producing polyhydroxyalkanoates under aerobic-anaerobic conditions," Journal of Industrial Microbiology and Biotechnology, vol. 35, no. 8, pp. 805-814, 2008.

[130] C. Kasemsap and C. Wantawin, "Batch production of polyhydroxyalkanoate by low-polyphosphate-content activated sludge at varying pH," Bioresource Technology, vol. 98, no. 5, pp. 1020 1027, 2007.

[131] M. Rodgers and G. Wu, "Production of polyhydroxybutyrate by activated sludge performing enhanced biological phosphorus removal," Bioresource Technology, vol. 101, no. 3, pp. 1049-1053, 2010.

[132] M. Majone, P. Massanisso, A. Carucci, K. Lindrea, and V. Tandoi, "Influence of storage on kinetic selection to control aerobic filamentous bulking," Water Science and Technology, vol. 34, no. 5-6, pp. 223-232, 1996.

[133] G. T. Daigger and C. P. L. Grady Jr., "The dynamics of microbial growth on soluble substrates. A unifying theory," Water Research, vol. 16, no. 4, pp. 365-382, 1982.

[134] M. Patel, D. J. Gapes, R. H. Newman, and P. H. Dare, "Physicochemical properties of polyhydroxyalkanoate produced by mixed-culture nitrogen-fixing bacteria," Applied Microbiology and Biotechnology, vol. 82, no. 3, pp. 545-555, 2009.

[135] B. Basak, O. Ince, N. Artan, N. Yagci, and B. K. Ince, "Effect of nitrogen limitation on enrichment of activated sludge for PHA production," Bioprocess and Biosystems Engineering, vol. 34, no. 8, pp. 1007-1016, 2011.

[136] K. Johnson, Y. Jiang, R. Kleerebezem, G. Muyzer, and M. C. M. van Loosdrecht, "Enrichment of a mixed bacterial culture with a high polyhydroxyalkanoate storage capacity," Biomacromolecules, vol. 10, no. 4, pp. 670-676, 2009.

[137] R. Moita and P. C. Lemos, "Biopolymers production from mixed cultures and pyrolysis by-products," Journal of Biotechnology, vol. 157, no. 4, pp. 578-583, 2012. 
[138] J. C. Fradinho, J. M. B. Domingos, G. Carvalho, A. Oehmen, and M. A. M. Ries, "Polyhydroxyalkanoates production by a mixed photosynthetic consortium of bacteria and algae," Bioresource Technology, vol. 132, pp. 146-153, 2013.

[139] M. G. E. Albuquerque, C. A. V. Torres, and M. A. M. Reis, "Polyhydroxyalkanoate (PHA) production by a mixed microbial culture using sugar molasses: effect of the influent substrate concentration on culture selection," Water Research, vol. 44, no. 11, pp. 3419-3433, 2010.

[140] H.-P. Shi, C.-M. Lee, and W.-H. Ma, "Influence of electron acceptor, carbon, nitrogen, and phosphorus on polyhydroxyalkanoate (PHA) production by Brachymonas sp. P12," World Journal of Microbiology and Biotechnology, vol. 23, no. 5, pp. 625-632, 2007.

[141] N. Mokhtarani, H. Ganjidoust, and E. V. Farahani, "Effect of process variables on the production of Polyhydroxyalkanoates by activated sludge," Iranian Journal of Environmental Health Science and Engineering, vol. 9, no. 1, pp. 1-7, 2012.

[142] E. Grothe, M. Moo-Young, and Y. Chisti, "Fermentation optimization for the production of poly( $\beta$-hydroxybutyric acid) microbial thermoplastic," Enzyme and Microbial Technology, vol. 25, no. 1-2, pp. 132-141, 1999.

[143] N. A. Aziz, C. S. Sipaut, and A. A.-A. Abdullah, "Improvement of the production of poly(3-hydroxybutyrate-co-3-hydroxyvalerate-co-4-hydroxybutyrate) terpolyester by manipulating the culture condition," Journal of Chemical Technology and Biotechnology, vol. 87, pp. 1607-1614, 2012.

[144] M. Suresh Kumar, S. N. Mudliar, K. M. K. Reddy, and T. Chakrabarti, "Production of biodegradable plastics from activated sludge generated from a food processing industrial wastewater treatment plant," Bioresource Technology, vol. 95, no. 3, pp. 327-330, 2004.

[145] M. M. Berekaa and A. M. Al Thawadi, "Biosynthesis of polyhydroxybutyrate (PHB) biopolymer by Bacillus megaterium SW1-2: application of Box-Behnken design for optimization of process parameters," African Journal of Microbiology Research, vol. 6, no. 4, pp. 838-845, 2012.

[146] M. Taran and H. Amirkhani, "Strategies of poly(3hydroxybutyrate) synthesis by Haloarcula sp. IRU1 utilizing glucose as carbon source: optimization of culture conditions by Taguchi methodology," International Journal of Biological Macromolecules, vol. 47, no. 5, pp. 632-634, 2010.

[147] C. Hong, H. Hao, and W. Haiyun, "Process optimization for PHA production by activated sludge using response surface methodology," Biomass and Bioenergy, vol. 33, no. 4, pp. 721$727,2009$.

[148] J. Quillaguamán, M. Muñoz, B. Mattiasson, and R. Hatti-Kaul, "Optimizing conditions for poly( $\beta$-hydroxybutyrate) production by Halomonas boliviensis LC1 in batch culture with sucrose as carbon source," Applied Microbiology and Biotechnology, vol. 74, no. 5, pp. 981-986, 2007.

[149] J. Quillaguamán, T. Doan-Van, H. Guzmán et al., "Poly(3hydroxybutyrate) production by Halomonas boliviensis in fedbatch culture," Applied Microbiology and Biotechnology, vol. 78, no. 2, pp. 227-232, 2008.

[150] S. V. Mohan and M. V. Reddy, "Optimization of critical factors to enhance polyhydroxyalkanoates (PHA) synthesis by mixed culture using Taguchi design of experimental methodology," Bioresource Technology, vol. 128, pp. 409-416, 2013.
[151] S. Samantaray, J. K. Nayak, and N. Mallick, "Wastewater utilization for poly- $\beta$-hydroxybutyrate production by the cyanobacterium Aulosira fertilissima in a recirculatory aquaculture system," Applied and Environmental Microbiology, vol. 77, no. 24, pp. 8735-8743, 2011.

[152] M. S. Kim, D. H. Kim, J. Cha, and J. K. Lee, "Effect of carbon and nitrogen sources on photo-fermentative $\mathrm{H} 2$ production associated with nitrogenase, uptake hydrogenase activity, and $\mathrm{PHB}$ accumulation in Rhodobacter sphaeroides KD131," Bioresource Technology, vol. 116, pp. 179-183, 2012.

[153] S. Venkata Mohan, M. Venkateswar Reddy, G. Venkata Subhash, and P. N. Sarma, "Fermentative effluents from hydrogen producing bioreactor as substrate for $\operatorname{poly}(\beta-\mathrm{OH})$ butyrate production with simultaneous treatment: an integrated approach," Bioresource Technology, vol. 101, no. 23, pp. 9382-9386, 2010.

[154] P. C. Lemos, C. Levantesi, L. S. Serafim, S. Rossetti, M. A. M. Reis, and V. Tandoi, "Microbial characterisation of polyhydroxyalkanoates storing populations selected under different operating conditions using a cell-sorting RT-PCR approach," Applied Microbiology and Biotechnology, vol. 78, no. 2, pp. 351360, 2008.

[155] E. Haba, J. Vidal-Mas, M. Bassas, M. J. Espuny, J. Llorens, and A. Manresa, "Poly 3-(hydroxyalkanoates) produced from oily substrates by Pseudomonas aeruginosa 47T2 (NCBIM 40044): effect of nutrients and incubation temperature on polymer composition," Biochemical Engineering Journal, vol. 35, no. 2, pp. 99-106, 2007.

[156] R. Hartmann, R. Hany, E. Pletscher, A. Ritter, B. Witholt, and M. Zinn, "Tailor-made olefinic medium-chain-length poly[ $[R)-3$ hydroxyalkanoates] by Pseudomonas putida GPol: batch versus chemostat production," Biotechnology and Bioengineering, vol. 93, no. 4, pp. 737-746, 2006.

[157] R. D. Ashby, D. K. Y. Solaiman, T. A. Foglia, and C.-K. Liu, "Glucose/lipid mixed substrates as a means of controlling the properties of medium chain length poly(hydroxyalkanoates)," Biomacromolecules, vol. 2, no. 1, pp. 211-216, 2001.

[158] S. R. Silva-Queiroz, L. F. Silva, J. G. C. Pradella, E. M. Pereira, and J. G. C. Gomez, "PHA ${ }_{\mathrm{MCL}}$ biosynthesis systems in Pseudomonas aeruginosa and Pseudomonas putida strains show differences on monomer specificities," Journal of Biotechnology, vol. 143, no. 2, pp. 111-118, 2009.

[159] B. S. Saharan, Anita, and P. Ranga, "Studies on production of PHB using soil isolates from irrigated agro-ecosystems," in Proceedings of 48th AMI Annual Conference of the Association entitled "Microbes: Biofactories of the future", Department of Biotechnology, Indian Institute of Technology Madras, Chennai, India, November 2008.

[160] B. S. Saharan, Ankita, and D. Sharma, "Bioplastics-for sustainable development: a review," International Journal of Microbial Resource Technology, vol. 1, no. 1, pp. 11-21, 2012.

[161] M. Venkateswar Reddy and S. Venkata Mohan, "Effect of substrate load and nutrients concentration on the polyhydroxyalkanoates (PHA) production using mixed consortia through wastewater treatment," Bioresource Technology, vol. 114, pp. 573582, 2012.

[162] D. Dionisi, M. Majone, G. Vallini, S. di Gregorio, and M. Beccari, "Effect of the applied organic load rate on biodegradable polymer production by mixed microbial cultures in a sequencing batch reactor," Biotechnology and Bioengineering, vol. 93, no. 1, pp. 76-88, 2006.

[163] H. Chen, H. Meng, Z. Nie, and M. Zhang, "Polyhydroxyalkanoate production from fermented volatile fatty acids: effect of 
$\mathrm{pH}$ and feeding regimes," Bioresource Technology, vol. 128, pp. 533-538, 2013.

[164] M. Villano, M. Beccari, D. Dionisi et al., "Effect of $\mathrm{pH}$ on the production of bacterial polyhydroxyalkanoates by mixed cultures enriched under periodic feeding," Process Biochemistry, vol. 45, no. 5, pp. 714-723, 2010.

[165] G. Ivanova, L. S. Serafim, P. C. Lemos, A. M. Ramos, M. A. M. Reis, and E. J. Cabrita, "Influence of feeding strategies of mixed microbial cultures on the chemical composition and microstructure of copolyesters $\mathrm{P}(3 \mathrm{HB}-\mathrm{co}-3 \mathrm{HV})$ analyzed by NMR and statistical analysis," Magnetic Resonance in Chemistry, vol. 47, no. 6, pp. 497-504, 2009.

[166] A. S. Ciggin, S. Rossetti, M. Majone, and D. Orhon, "Effect of feeding regime and the sludge age on the fate of acetate and the microbial composition in sequencing batch reactor," Journal of Environmental Science and Health A, vol. 47, no. 2, pp. 192-203, 2012.

[167] A. Nath, M. Dixit, A. Bandiya, S. Chavda, and A. J. Desai, "Enhanced PHB production and scale up studies using cheese whey in fed batch culture of Methylobacterium sp. ZP24," Bioresource Technology, vol. 99, no. 13, pp. 5749-5755, 2008.

[168] D. Dionisi, M. Majone, V. Papa, and M. Beccari, "Biodegradable polymers from organic acids by using activated sludge enriched by aerobic periodic feeding," Biotechnology and Bioengineering, vol. 85, no. 6, pp. 569-579, 2004.

[169] J. G. da Cruz Pradella, J. L. Ienczak, C. R. Delgado, and M. K. Taciro, "Carbon source pulsed feeding to attain high yield and high productivity in poly(3-hydroxybutyrate) (PHB) production from soybean oil using Cupriavidus necator," Biotechnology Letters, vol. 34, no. 6, pp. 1003-1007, 2012.

[170] G. J. Kim, I. Y. Lee, S. C. Yoon, Y. C. Shin, and Y. H. Park, "Enhanced yield and a high production of medium-chainlength poly(3-hydroxyalkanoates) in a two-step fed-batch cultivation of Pseudomonas putida by combined use of glucose and octanoate," Enzyme and Microbial Technology, vol. 20, no. 7, pp. 500-505, 1997.

[171] S. S. Cameotra and R. S. Makkar, "Synthesis of biosurfactants in extreme conditions," Applied Microbiology and Biotechnology, vol. 50, no. 5, pp. 520-529, 1998.

[172] G. Soberón-Chávez, M. Aguirre-Ramírez, and R. Sánchez, "The Pseudomonas aeruginosa RhlA enzyme is involved in rhamnolipid and polyhydroxyalkanoate production," Journal of Industrial Microbiology and Biotechnology, vol. 32, no. 11-12, pp. 675-677, 2005.

[173] A. A. Pantazaki, C. P. Papaneophytou, and D. A. Lambropoulou, "Simultaneous polyhydroxyalkanoates and rhamnolipids production by Thermus thermophilus HB8," AMB Express, vol. 1, no. 1, pp. 1-13, 2011.

[174] M. Nitschke, S. G. V. A. O. Costa, and J. Contiero, "Rhamnolipids and PHAs: recent reports on Pseudomonas-derived molecules of increasing industrial interest," Process Biochemistry, vol. 46, no. 3, pp. 621-630, 2011.

[175] S. Pal, A. Manna, and A. K. Paul, "Production of $\operatorname{poly}(\beta-$ hydroxybutyric acid) and exopolysaccharide by Azotobacter beijerinckii WDN-01," World Journal of Microbiology and Biotechnology, vol. 15, no. 1, pp. 15-21, 1999.

[176] L. Lama, B. Nicolaus, V. Calandrelli, M. C. Manca, I. Romano, and A. Gambacorta, "Effect of growth conditions on endoand exopolymer biosynthesis in Anabaena cylindrica 10 C," Phytochemistry, vol. 42, no. 3, pp. 655-650, 1996.
[177] J. Turner, G. Sverdrup, M. K. Mann et al., "Renewable hydrogen production," International Journal of Energy Research, vol. 32, no. 5, pp. 379-407, 2008.

[178] M. Vincenzini, A. Marchini, A. Ena, and R. de Philippis, " $\mathrm{H}_{2}$ and poly- $\beta$-hydroxybutyrate, two alternative chemicals from purple non sulfur bacteria," Biotechnology Letters, vol. 19, no. 8, pp. 759-762, 1997.

[179] M. A. Hassan, Y. Shirai, N. Kusubayashi, M. I. A. Karim, K. Nakanishi, and K. Hashimoto, "Effect of organic acid profiles during anaerobic treatment of palm oil mill effluent on the production of polyhydroxyalkanoates by Rhodobacter sphaeroides," Journal of Fermentation and Bioengineering, vol. 82, no. 2, pp. 151-156, 1996.

[180] A. Scoma, L. Bertin, and F. Fava, "Effect of hydraulic retention time on biohydrogen and volatile fatty acids production during acidogenic digestion of dephenolized olive mill wastewaters," Biomass and Bioenergy, vol. 48, pp. 51-58, 2013.

[181] D. Dionisi, M. Majone, G. Vallini, S. di Gregorio, and M. Beccari, "Effect of the length of the cycle on biodegradable polymer production and microbial community selection in a sequencing batch reactor," Biotechnology Progress, vol. 23, no. 5, pp. 1064-1073, 2007.

[182] H. F. Chang, W. C. Chang, and C. Y. Tsai, "Long-term effect of weak nitrogen limitation on polyhydroxyalkanoates production of propionate-fed activated sludge operated at long sludge retention time," World Journal of Microbiology and Biotechnology, vol. 28, no. 11, pp. 3113-3122, 2012.

[183] K. A. Third, M. Newland, and R. Cord-Ruwisch, "The effect of dissolved oxygen on PHB accumulation in activated sludge cultures," Biotechnology and Bioengineering, vol. 82, no. 2, pp. 238-250, 2003.

[184] A. Poli, P. di Donato, G. R. Abbamondi, and B. Nicolaus, "Synthesis, production, and biotechnological applications of exopolysaccharides and polyhydroxyalkanoates by Archaea," Archaea, vol. 2011, Article ID 693253, 13 pages, 2011. 

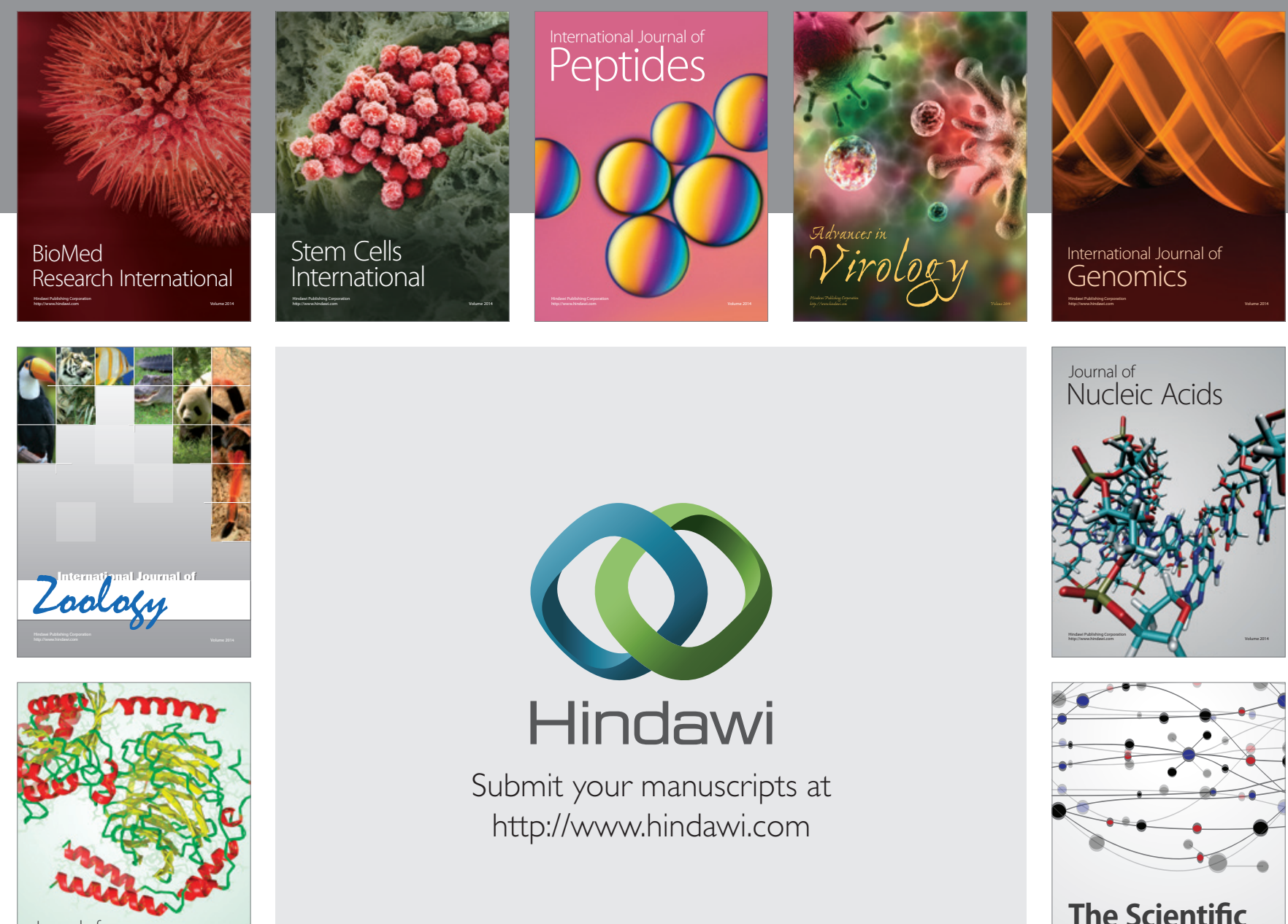

Submit your manuscripts at

http://www.hindawi.com

Journal of
Signal Transduction
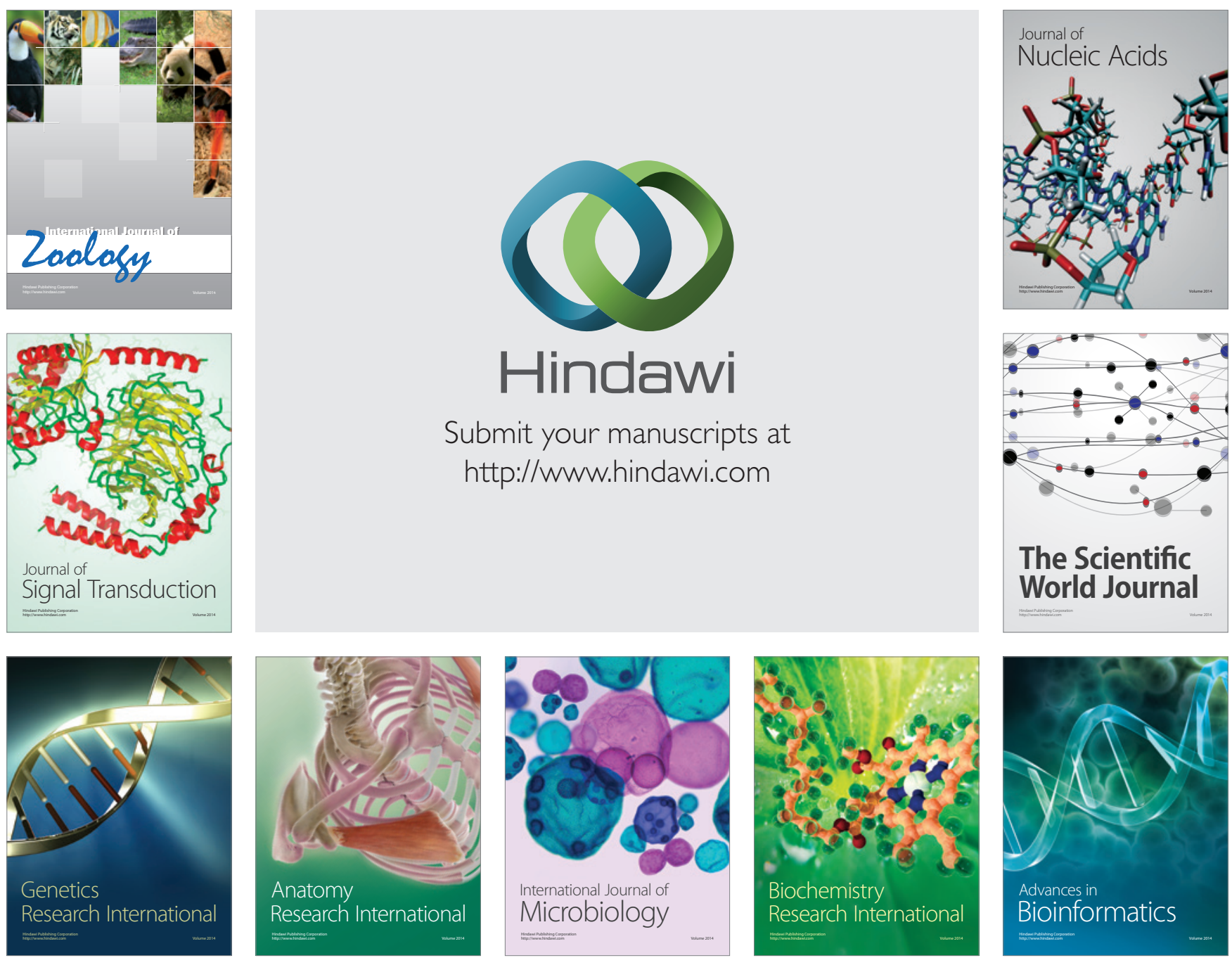

The Scientific World Journal
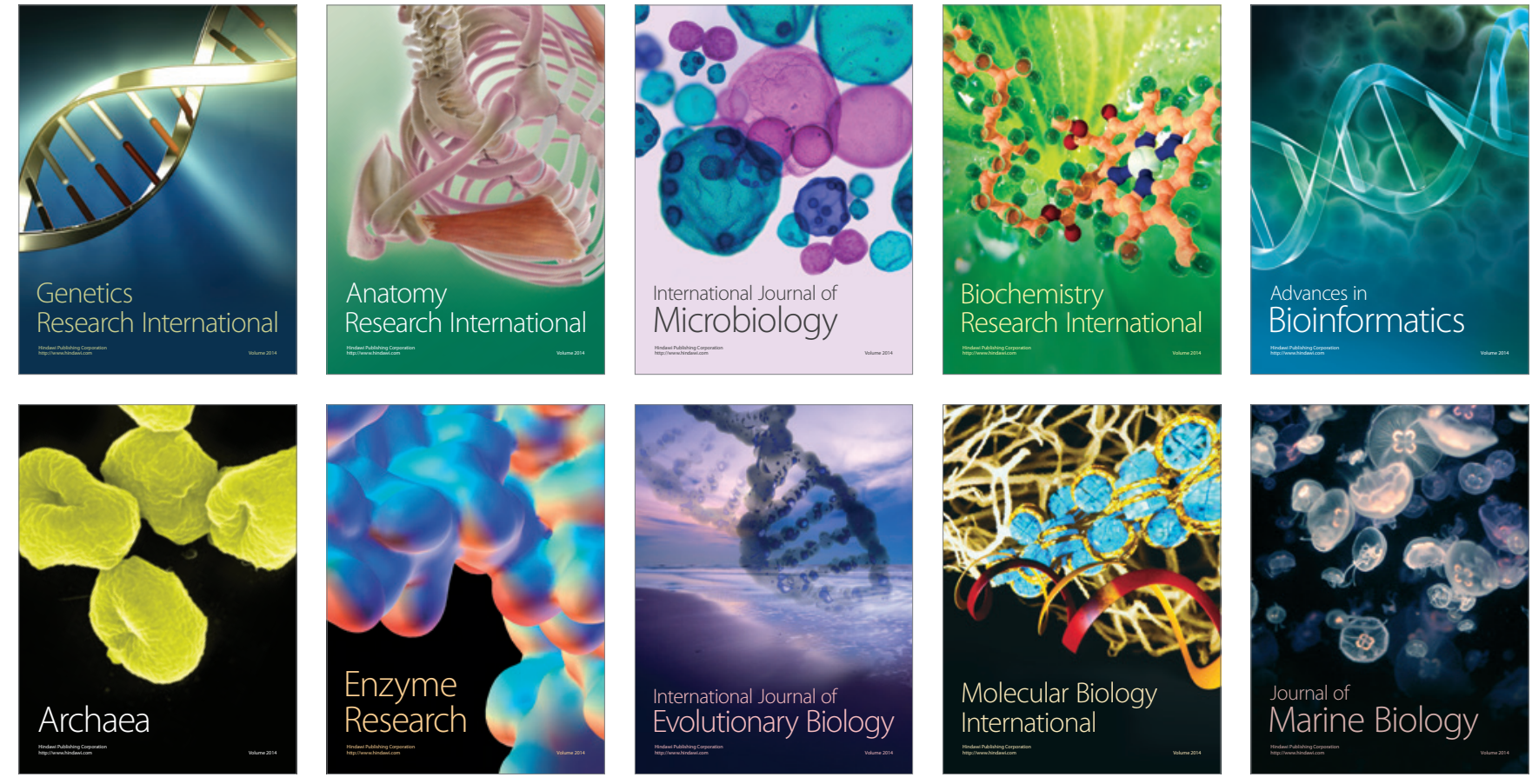